\title{
CARACTERÍSTICAS DEL SISTEMA CIENTÍFICO Y TECNOLÓGICO DE MÉXICO
}

\author{
Fernando Chávez \\ ÁNGEL DE LA VEGA \\ Ale Jandro NADAL \\ El Colegio de México
}

\section{INTRODUCCIÓN}

EL PRopósito de este trabajo es identificar los rasgos fundamentales del sistema científico y tecnológico (SCT) de México. ${ }^{1}$ Con este fin se presenta un examen de las relaciones entre los diferentes componentes del sistema, así como del grado de vinculación entre esas unidades y los sectores productivo y educativo. También se incluye un examen de las relaciones existentes con los sistemas científicos de otros países. El análisis que se presenta a continuación constituye un diagnóstico preliminar que es utilizado en un proyecto de investigación más amplio sobre mecanismos de política científica y tecnológica. ${ }^{2}$

La utilización del concepto de sistema científico y tecnológico responde a la necesidad de dar un tratamiento analítico ordenado a la gran cantidad de variables que condicionan el desarrollo científico y tecnológico. Es importante señalar que las fuentes de información han sido un problema permanente en los trabajos sobre el tema en México. No existe un trabajo integral que analice con una metodología rigurosa el estado actual del desarrollo científico y tecnológico, aunque desde luego se pueden encontrar en la literatura algunos trabajos, con enfoques muy diversos, que esclarecen en buena medida el problema. Sin embargo, su utilización en este trabajo, así como el manejo de estadísticas sobre el esfuerzo científico-tecnológico estuvo precedida de una cuidadosa revisión y crítica. ${ }^{3}$

1 El sistema científico y tecnológico está integrado por el conjunto de instituciones o unidades que de una manera permanente se dedican a la generación, adaptación, aplicación, transformación y difusión del conocimiento científicotecnológico. También se incluyen las actividades de coordinación, financiamiento, planeación y formulación de políticas sobre el desarrollo científico y tecnológico.

$2 \mathrm{El}$ proyecto sobre mecanismos de política científica y tecnológica se lleva a cabo en forma simultánea en once países con financiamiento del Centro Internacional de Investigaciones para el Desarrollo del gobierno canadiense y en forma complementaria, del Departamento de Asuntos Científicos de la Organización de Estados Americanos para algunos países del área latinoamericana.

3 Además se preparó un cuestionario que se sometió a nueve centros de investigación y desarrollo experimental en diferentes áreas. Se visitaron otros tres 


\section{EL SISTEMA CIENTÍFICO-TECNOLÓGICO Y SU VINCULACIÓN CON EL APARATO PRODUCTIVO}

El examen de las condiciones actuales del SCT, revela que no existe en México un sistema integrado de generación, difusión y utilización de conocimientos científicos y tecnológicos. Existe por una parte una serie de centros o institutos de investigación y desarrollo experimental (IDE) que llevan a cabo una actividad sistemática de investigación: funcionan aproximadamente 312 instituciones en las diferentes áreas de la ciencia y la tecnología. ${ }^{4}$ En términos generales, estas unidades están desvinculadas del aparato económico en lo que concierne a la investigación propiamente dicha. ${ }^{5}$

En aquellos sectores en los que la actividad productiva está a cargo del sector público, existe una mayor vinculación entre la IDE y la producción. Tal es el caso de la industria del petróleo y la petroquímica básica, así como de la generación de energía eléctrica. En otros sectores en los que el Estado ha tenido que llenar un vacío en cuanto a la prestación de servicios técnicos de apoyo a la producción (sector agropecuario), $\mathrm{o}$ en los que es el principal responsable de la prestación de un servicio público (sector biomédico), se ha desarrollado también un vínculo más estrecho con el esfuerzo de la IDE. Pero en términos generales la investigación científica y tecnológica no está integrada a la producción de bienes y servicios de una manera generalizada y sistemática.

Esta situación se debe en parte al hecho de que el proceso de desarrollo de las fuerzas productivas ha sido tal que se ha acentuado la vinculación tecnológica con el exterior, en lugar de establecerse una relación estrecha con un sistema local de generación de conocimientos. No existe una "demanda" efectivamente planteada por el aparato productivo al SCT nacional. Una gran parte de los mecanismos de política económica

centros de investigación en los que no fue posible aplicar el cuestionario pero que proporcionaron información sobre varios puntos. Un segundo cuestionario fue utilizado en entrevistas en dos empresas de ingeniería. Si bien ambos cuestionarios tuvieron un carácter exploratorio, sirvieron para plantear algunos problemas que habían sido descuidados en la literatura existente en México. La información obtenida sirvió para la presentación y consideración de algunas hipótesis, así como para juzgar la calidad de la información de fuentes secundarias disponible actualmente. El equipo de investigación desea agradacer la colaboración de Joseph Hodara y Juan José Cantú.

4 Esta cifra no incluye las instituciones en el campo de las ciencias sociales ni el Servicio Nacional de Extensión Agrícola. Un estudio del Instituto Nacional de la Investigación Científica (INIC) registró un total de 375 instituciones incluyendo las de las ciencias sociales y el Servicio de Extensionismo. (Véase Política nacional y. programas en ciencia y tecnología, INIC, México, 1970.) Posteriormente, el Centro de Diagnóstico del conacyT presentó la cifra de 313 instituciones, pero agrupó tanto a centros de IDE como a instituciones que prestan apoyo a la investigación.

5 Sobre el grado de cohesión existente en el interior del sistema científicotecnológico véase más adelante la sección VIII sobre las funciones de coordinación y fomento de los IDE. 
actualmente vigentes no favorecen y aun frenan la incorporación de conocimientos técnicos a la producción. Además, la mayor parte de los centros de IDE carecen de una política activa de vinculación con unidades productivas (visitas regulares, oferta de servicios, etc.). De los nueve centros visitados (para la elaboración de este informe), solamente uno tenía un programa de actividades sistemáticamente dirigidas hacia el establecimiento de un nexo con unidades productivas (aun en ese caso, se trata de un centro de investigaciones del sector público directamente vinculado a la producción en una rama que controla el Estado: su política de vinculación con empresas se restringe a las empresas del sector público). Es muy probable que esta circunstancia no esté generalizada a todo el SCT. Sin embargo, si se piensa que un gran número de centros de investigación está incrustado en las instituciones de enseñanza superior, o directamente dependen del sector público, ${ }^{6}$ y que su presupuesto está más o menos asegurado anualmente, es muy probable que la proporción de centros de IDE que cuenta con una política activa de vinculación al sistema económico sea en extremo reducida.

El esfuerzo de investigación y desarrollo experimental se ha orientado así hacia una actividad con poca relación con la producción. Pero además, en términos generales no existe una orientación clara de la investigación hacia la solución de muchos de los problemas que plantea el subdesarrollo del país. Desde luego no puede afirmarse lo anterior en el caso de centros de investigación directamente vinculados con una rama de la producción (por ejemplo, energéticos o sector agropecuario), o tratándose de algunos nuevos centros de IDE (por ejemplo, el Centro de Oceanografía Física y Experimental en Baja California o el de Investigación Ecológica del Sureste situado en San Cristóbal de las Casas, Chiapas). Pero en general los institutos de investigación no cuentan con un programa de actividades dirigido hacia la preparación de un diagnóstico tanto técnico como socioeconómico sobre los problemas del subdesarrollo que se presentan en su esfera de acción. Como consecuencia, una proporción elevada de la IDE en el país se orienta hacia actividades de investigación básica. Sobre este punto existen diversos cálculos que utilizan como indicador el gasto en investigación básica (IB) como porciento del gasto total en IDE, y que van desde $44 \%{ }^{7}$ hasta $50 \% .^{8}$ El porciento re-

6 Del total de investigadores que trabajan en ocho campos de investigación, entre $54 \%$ y $100 \%$ se localizan en las instituciones de educación superior. El sector público absorbe, en los casos de las ciencias biomédicas y agropecuarias forestales, el $55.3 \%$ y $82.6 \%$ respectivamente. El caso extremo se observa en la investigación sobre aplicaciones tecnológicas y fomento industrial, pues en apariencia el sector público es el único que mantiene a un cuerpo de investigadores en este campo tan relevante. Véase el cuadro 2.

7 Respuesta del CONACYT a la "Encuesta anual sobre personal y gastos de investigación y desarrollo experimental" de la UNEsco, cuadro 6. El gasto se distribuye así: $44 \%$ en investigación básica, $29 \%$ en investigación aplicada y $27 \%$ en desarrollo experimental. (Los cálculos incluyen ciencias sociales.)

8 INIC, Política nacional..., op. cit., p. 42. Esta estimación incluye los gastos en ciencias sociales. 
sulta muy elevado si se considera que en los países europeos y en Estados Unidos el gasto en Iв fluctúa entre $10 \%$ y $20 \%$ del gasto total. Es evidente que en términos absolutos, el gasto en investigación básica en estos últimos países es muy superior al de México.

En consecuencia, el plan de trabajo de los centros de IDE no depende de las demandas explícitas de los usuarios del conocimiento. Así, el plan de trabajo es elaborado en su mayor parte tomando en consideración los planes internos de la institución (aunque no necesariamente en función de los requerimientos de conocimientos del proceso de desarrollo).

Aunque no existe una vinculación entre la IDE y el aparato productivo, esto no quiere decir que las instituciones de investigación no tengan ninguna relación con actividades productivas. En algunos casos existe una relación a nivel de la prestación de servicios técnicos: éste puede interpretarse como el estado embrionario de una relación más completa a nivel de la investigación propiamente dicha. Sin embargo, existen indicios de que los principales demandantes de servicios técnicos a los centros de IDE son, por una parte, empresas extranjeras que operan en México; y por otra, grandes empresas que no solamente tienen los recursos para acudir al SCT, sino también la capacidad de explicitar una demanda de conocimientos y servicios técnicos. Así, un centro de investigaciones tecnológicas para la industria reveló que el $100 \%$ de los servicios que proporcionaba a empresas consistían en servicios técnicos específicos, y el $75 \%$ de las empresas que los solicitaban eran empresas extranjeras. Es evidente que dichas empresas recurren al sistema científicotecnológico nacional básicamente para la solución de problemas técnicos muy específicos, tales como adaptaciones en los procesos, pruebas y otro tipo de servicios secundarios. ${ }^{9}$

Finalmente, es importante agregar que cuando la actividad de IDE está vinculada con la producción, la investigación realizada no siempre es la más idónea. En el sector agropecuario, por ejemplo, la investi-

9 En términos generales son muy pocas las actividades de IDE que llevan a cabo las filiales de las corporaciones transnacionales que operan en México. Las consideraciones de economías externas y de escala, así como las limitaciones de "masas críticas" de investigadores para proyectos específicos de IDE, dan lugar a la concentración de las actividades de investigación en un laboratorio de la casa matriz. La estrategia global de la empresa transnacional consiste en que posteriormente distribuye los costos de la IDE realizada en la matriz entre las subsidiarias (aunque éstas no se hayan beneficiado directamente por esas inversiones). Dicha distribución se puede hacer vía diversos canales: sobrefacturando el envío de materias primas o productos intermedios, subfacturando las exportaciones de la subsidiaria hacia la matriz, o en los pagos de intereses por préstamos entre las filiales. Véase Constantino V. Vaitsos, "Income Generation and Income Distribution in the Foreign Direct Investment Model", Universidad Harvard, tesis doctoral (inédita), 1971. Otros estudios recientes comprueban también esta tendencia: Jack Behrman, Some Patterns in the Rise of Multinational Enterprise, Chapel Hill, University of North Carolina, 1969; y Jack Baranson, "Transfer of Technology and the Developing World: Conflict and Accommodation”, Canberra, abril de 1973. 
gación está orientada en general hacia el sector moderno de la producción. Un estudio reciente ha demostrado que la manera misma como se proyectan los experimentos en este campo es fruto de una concepción científica derivada de la práctica agrícola norteamericana, campo en el que la estructura de insumos puede calificarse de opulenta frente a la agricultura de subsistencia en el sector tradicional. Además la IDE se concentra en zonas de riego y alrededor de algunos cultivos comerciales. Así, los resultados producidos sólo pueden ser aprovechados "casi exclusivamente por los agricultores ricos que cultivan la tierra con patrones comerciales, que tienen amplio acceso al crédito y que en consecuencia pueden contratar la mano de obra y adquirir los insumos necesarios". ${ }^{10}$ Así por ejemplo, nunca se han investigado las implicaciones tecnológicas de una producción más intensiva en uso de mano de obra rural (a pesar de que parece existir una tendencia hacia la substitución de mano de obra por maquinaria: la erogación por trabajo asalariado dentro de los costos de producción bajó del 22 al 7\% entre 1940 y 1960; en ese mismo período los costos por concepto de maquinaria subieron de $6 \%$ a $11 \%$ del costo total).$^{11}$

Otro indicador de la desvinculación entre la IDE y la producción es el escaso registro de patentes por parte de los centros de investigación (ya pertenezcan al sector público o al privado). Los cálculos sobre registro de patentes en México revelan que la aplastante mayoría son regis-

10 Julio Boltvinik, "Economías campesinas e investigación agrícola", México, 1973 (inédito). Es justo señalar la toma de conciencia entre los investigadores del sector agropecuario frente a esta problemática. En los últimos años se ha buscado atenuar este sesgo en la IDE agrícola. Ejemplo de esto es el "Plan Puebla", en el que el Centro Internacional de Mejoramiento del Maíz y del Trigo ha trabajado con autoridades del gobierno federal y estatal en una región de 116000 hectáreas con 47000 familias campesinas a unos 100 kilómetros al este de la ciudad de México. El plan gira alrededor de un programa de producción de maíz con pequeños agricultores. Otro esfuerzo reciente por alterar esta situación es el establecimiento del "Plan Chapingo" que busca integrar las actividades de enseñanza, investigación y extensión agrícola en el Centro Nacional de Enseñanza, Investigación y Extensión Agrícola ubicado en Chapingo, estado de México. Sobre este punto consúltese a Jorge Suárez Villada, "Diagnóstico de las investigaciones agrícolas y animales", CONACYT, 1972 (mimeografiado). Resulta difícil evaluar el impacto de la IDE sobre el sector agrícola y pecuario, y existen posiciones encontradas sobre este punto: véase Nicolás Ardito-Barletta, "El crecimiento de la agricultura mexicana y de los cultivos sujetos al programa de investigación, 1940-1964" y Folke Dovring, "Reforma agraria y productividad: el caso mexicano", ambos en La economía mexicana, Leopoldo Solís, (Comp.), México, Fondo de Cultura Económica, 1973. En general el sector tradicional ha dependido de los incrementos de los insumos convencionales (trabajo y tierra) para aumentar su producción: véase el estudio de Montague Yudelman, Gavan Butler, Ranadeo Banerji, Technological Change in Agriculture and Employment in Developing Countries, OECD, París, 1971, con especial referencia al caso de México.

11 Sergio Reyes Osorio y Salomón Eckstein, "El desarrollo polarizado de la agricultura mexicana", en Crecimiento o desarrollo económico, M. Wionczek, (Comp.) México, SEP-setentas, 1971. 
tradas por extranjeros: se calcula que $90 \%$ de las patentes registradas en los últimos diez años pertenecen a empresas extranjeras. ${ }^{12}$

En este campo México sigue reconociendo el Convenio de París, lo cual impone restricciones fundamentales para utilizar al sistema de patentes como un instrumento de política tecnológica. En primer lugar, dicho tratado consagra el principio de la reciprocidad de trato a extranjeros y nacionales, olvidando el hecho de que la reciprocidad sólo tiene sentido entre iguales. En segundo término, el Convenio de París señala que las patentes otorgan al titular el privilegio exclusivo para importar el producto patentado o producido con el proceso patentado. A través de este derecho se restringe la competencia y se puede controlar un mercado sin necesidad de realizar inversiones adicionales. Pero además es necesario señalar que la legislación sobre la propiedad industrial es anticuada y otorga privilegios durante plazos excesivos (hasta 15 años para patentes de invención). Además, se trata de un instrumento de política que facilita la no explotación de las patentes registradas. No existen estudios detallados sobre el funcionamiento del sistema de patentes en México, pero dada la excesiva vinculación tecnológica con el exterior no hay razones para pensar que la situación sea diferente de la de otros países latinoamericanos en los que la proporción de patentes no explotadas que son utilizadas exclusivamente para restringir la competencia es altísima. ${ }^{13}$ Por otra parte, las disposiciones legales para la concesión de licencias obligatorias han anulado la posibilidad de utilizar este mecanismo para obligar al titular de una patente a explotarla. Así, la Ley de Propiedad Industrial establece que en caso de concederse una licencia obligatoria, el licenciatario debe compartir "la mitad de las ganancias líquidas resultado de la explotación respectiva" con el titular de la patente (art. 61). Además, el titular de la patente está expresamente facultado para pedir la revocación de la licencia obligatoria pasado un plazo de dos años si decide explotar por sí mismo la patente correspondiente. Como resultado, ante el peligro de que el titular de la patente haga valer este derecho, nadie recurre a solicitar una licencia obligatoria.

Como consecuencia del análisis anterior se desprende el hecho de

12 Véase Mauricio Campos "Transferencia de tecnología y el desarrollo económico de México”, México, 1973 (inédito). El cálculo más optimista señala que el $85 \%$ de las solicitudes de patentes recibidas en México en un año son de origen extranjero (anualmente se reciben, 9000 solicitudes de patentes y 5000 de marcas), véase Mayer Gabay, "Industrial Property and Technological Information Services in the Context of Regional Economic Integration in Latin America", OEA, Departamento de Asuntos Científicos, 1971 (mimeografiado).

13 Sobre este punto véanse los siguientes trabajos: Gastón Oxman y Francisco Sagasti, "La transferencia de tecnología hacia los países del Grupo Andino", oEA, Departamento de Asuntos Científicos, 1972 (mimeografiado); Francisco Biato, Eduardo Guimaraes y María Poppe de Figueredo, "A transferencia de tecnología no Brasil", Río de Janeiro, IPEA, 1970; Jorge Katz y Daniel Chudnovsky, "Patentes y actividad inventiva local", Argentina, Instituto Di Tella, 1971 (mimeografiado); Constantino V. Vaitsos, "Patentes Revisited", Junta de Acuerdo de Cartagena, Lima, 1971. 
que existe una tendencia hacia la concentración del progreso técnico en los sectores que cuentan con una participación mayoritaria en la producción del excedente económico. Además, la información obtenida tiende a confirmar las hipótesis que se han formulado sobre la heterogeneidad creciente del sistema económico a través de la escasa difusión del progreso técnico.

\section{LAS RELACIONES ENTRE LA IDE EN MÉXICO Y EL EXTERIOR}

Como ya se ha señalado, lo anterior es una de las causas de que el esfuerzo de investigación esté orientado hacia un trabajo de investigación básico en comparación con la investigación aplicada y el desarrollo experimental que se lleva a cabo. Sin embargo, existen indicios de que la investigación básica que se realiza está en función de la problemática planteada por las investigaciones fundamentales realizadas en los países industrializados. En primer lugar, es en estos países en donde se eroga el $98 \%$ del gasto mundial en IDE, ${ }^{14}$ y obviamente ahí también se lleva a cabo la casi totalidad del esfuerzo de investigación pura, no orientada. Es este tipo de investigación la que produce conocimientos básicos y definiciones de "nuevos problemas" (rebasando o solucionando los problemas ya conocidos); o en los términos empleados por Thomas S. Kuhn, esta investigación, de un alto contenido exploratorio es la que define nuevos "paradigmas".15 En segundo lugar, la investigación básica, libre y exploratoria resulta muy costosa y plantea la existencia de economías de escala y de economías externas: servicios de infraestructura bastante completos y eficientes (servicios de información y documentación, procesamiento electrónico de datos, recolección de información y levantamiento de inventarios y servicios cartográficos, meteorológicos, etc.) En consecuencia, este tipo de investigación se lleva a cabo en los países industrializados que cuentan con los recursos humanos y financieros mínimos necesarios y con la infraestructura científica indispensable. Esto no quiere decir que no se lleve a cabo investigación básica no orientada en un país como México; pero lo más probable es que se trate de un esfuerzo alrededor de paradigmas definidos por la IB en otros países. En varias instancias se ha hablado del "carácter repetitivo" de una parte importante de la investigación en México. ${ }^{16}$ Es revelador lo señalado por un

14 "Draft Introductory Statement for the World Plan of Action for the Application of Science and Technology to Development, Prepared by the Sussex Group", en el documento Science and Technology for Development (UN.ST-ECA/133). El cálculo está basado en datos de la oCDE, UNEsco y la Unión Panamericana. Se excluyen las economías centralmente planificadas.

15 Thomas S. Kuhn, La estructura de las revoluciones científicas, México, Fondo de Cultura Económica, 1971. Por "paradigma" se entiende una realización universalmente reconocida que durante un cierto tiempo proporciona modelos de problemas y soluciones a una comunidad científica.

16 Véanse las declaraciones del Dr. Luis Cañedo en la Reunión sobre la Ciencia en México, "Diorama", Suplemento cultural de Excélsior, 14 de abril de 1974, p. 10. 
científico mexicano: “. . . en el seno mismo de la investigación científica en México muchos de los problemas abordados forman parte integrante de programas elaborados en el extranjero y realizados en su mayor parte en otros países". ${ }^{17}$ En este sentido destaca también un examen reciente de la IDE en México realizado por un neurofisiólogo, en el que se explica cómo un investigador que regresa del exterior se concreta a buscar los "medios necesarios para continuar la idea o el tema practicado en el extranjero, con la esperanza de convertirse en el individuo que proporcione una pieza clave del engranaje que se elabora en alguna otra institución extranjera". ${ }^{18}$ El carácter polémico de este punto no invalida el que deban explorarse con más detenimiento las implicaciones de la división internacional del trabajo científico.

Es necesario examinar las implicaciones del proceso de formación de recursos humanos a nivel de investigadores y científicos para países subdesarrollados cuando se recurre a la realización de estudios de posgrado o de investigaciones en países industrializados. ${ }^{19} \mathrm{Al}$ regresar a su país de origen, el nuevo investigador frecuentemente lleva consigo un enfoque sobre: a) la naturaleza de la ciencia (la ciencia considerada como una y universal, independientemente del marco socioeconómico en que se desarrolla) y una convicción generalizada de que el desarrollo de la ciencia a escala mundial se ha llevado a cabo históricamente mediante un proceso acumulativo; b) los problemas que son la última novedad en su especialidad, así como la metodología y aun el instrumental y equipo necesario para abordarlos. Este conjunto de elementos ha influido profundamente en la orientación de la investigación en México en los últimos años. En fechas recientes se ha estado proponiendo el envío de estudiantes de posgrado al extranjero solamente cuando el estudiante haya tenido un contacto más estrecho con la realidad del subdesarrollo én el país (a través de un servicio social o algún otro mecanismo) ${ }^{20}$ Sin embargo, los defectos del proceso explicado se reflejan en el hecho de que en un país con más de 10000 kilómetros de costas, en 1969 sólo el $20 \%$ de los investigadores realizaban actividades de IDE en las ciencias del mar, y $3.0 \%$ trabajaba en aplicaciones tecnológicas y fomento

17 Ver Guillermo Haro, "El desarrollo de la ciencia en México", revista Espejo, Núm. 2, 1967.

18 Véase el artículo del Dr. Xavier Lozoya (de la División de Neurofisiología del Departamento de Investigación Científica del imss), "Estado actual de la investigación científica en México", suplemento dominical Núm, 588, El Día, 30 de septiembre de 1973.

19 De una encuesta realizada en 1969 sobre 1215 investigadores (aproximadamente un $43 \%$ del total de 2222 investigadores que arroja el cálculo del INIC), el $52.5 \%$ había realizado estudios de posgrado en el extranjero. María Luisa Rodríguez Sala de Gomezgil, Las instituciones de investigación científica en México, UNAM-INIC, México, 1970. Este estudio incluye la investigación en ciencias sociales.

20 Este criterio se siguió en el primer período del programa de becas del Banco de México, hacia 1945-1946. 
industrial. ${ }^{21}$ En un país de grandes extensiones de zonas áridas existen muy pocos centros de investigación sobre los problemas de estas regiones. Los centros especializados en la materia carecen de recursos humanos y financieros para realizar un trabajo relevante. El cuadro 1 muestra el número de investigadores por disciplinas y sector de dependencia.

El hecho de que no exista una vinculación de la investigación científica con la problemática del desarrollo en México, se ve agravado por el funcionamiento interno de la gran mayoría de centros de IDE que operan en el país. Además de la carencia de una política de vinculación con unidades productivas y la falta de un programa de identificación de "problemas del desarrollo", el proceso de toma de decisiones en el interior de los centros de investigación está muy centralizado a nivel de los directores y jefes de departamento.

El trabajo en equipos interdisciplinarios es por otra parte muy raro. Un estudio reciente reveló que de un total de 1309 investigaciones en curso, 798 eran llevadas a cabo por un solo investigador de tiempo completo: es decir, el $61 \%$ de la muestra no eran trabajos de carácter interdisciplinarios. ${ }^{22}$ Esto es un elemento de gran importancia si se parte de la hipótesis de Piaget sobre la investigación científica actual. ${ }^{23}$ Para este autor, la investigación tiende a ser cada vez más un esfuerzo interdisci-

21 INIC, Política nacional y programas en ciencia y tecnología, México, 1970. Los porcientos son sobre el total de investigadores que incluye a los de las ciencias sociales. El mismo estudio estimó que para 1970 México requeriría 38000 agrónomos y sólo tenía 6000 en 1969. Es también reveladora la declaración de Guillermo Haro, Director del Instituto de Astrofísica, Optica y Electrónica, en la reunión de trabajo del presidente Echeverría con la comunidad científica mexicana, celebrada en los Pinos el 29 de noviembre de 1972, en el sentido de que en el país existen muy pocos "geólogos mexicanos de alto nivel; en un país en donde abundan minerales, no tenemos un grupo mínimamente decoroso de químicos inorgánicos o de especialistas en estado sólido; en un país en donde hay más de 160 plantas maquiladoras electrónicas, contamos con un número despreciable de especialistas a nivel internacional en electrónica, y podría así seguir enumerando campos", Excélsior, 30 de noviembre de 1972.

22 María Luisa Rodríguez Sala de Gomezgil, Las instituciones de investigación científica en México, op. cit., pp. 38-39. Además, el hecho de que en el $39 \%$ restante hubieran participado dos o más investigadores no quiere decir que esos trabajos hayan sido interdisciplinarios.

23 Jean Piaget, "L'épistemologie des relations interdisciplinaires", ponencia presentada en el Seminario de la OCDE sobre "Pluridisciplinareidad e Interdisciplinareidad en las universidades", Niza, septiembre de 1970. Véase también a Jean Piaget, W. I. M. Mackenzie, Paul F. Lazarsfeld y otros, Tendencias de la investigación de las ciencias sociales, Alianza Editorial, UNESCO, Madrid, 1973. El capítulo introductorio a cargo de Piaget sobre la situación de las "ciencias del hombre" dentro del sistema de las ciencias contiene una interesante discusión sobre la inexistencia de un sistema jerárquico lineal de las ciencias y se presenta un modelo de clasificación circular en el que "ninguna de las ciencias puede ser situada en un solo plano sino que cada una de ellas admite distintos niveles jerárquicos... y el orden de las ciencias vuelve a ser circular”, pp. 104-105. En conclusión, se enfatiza la importancia de la investigación interdisciplinaria para la investigación científica crítica, tanto en las ciencias naturales como en las ciencias sociales. 


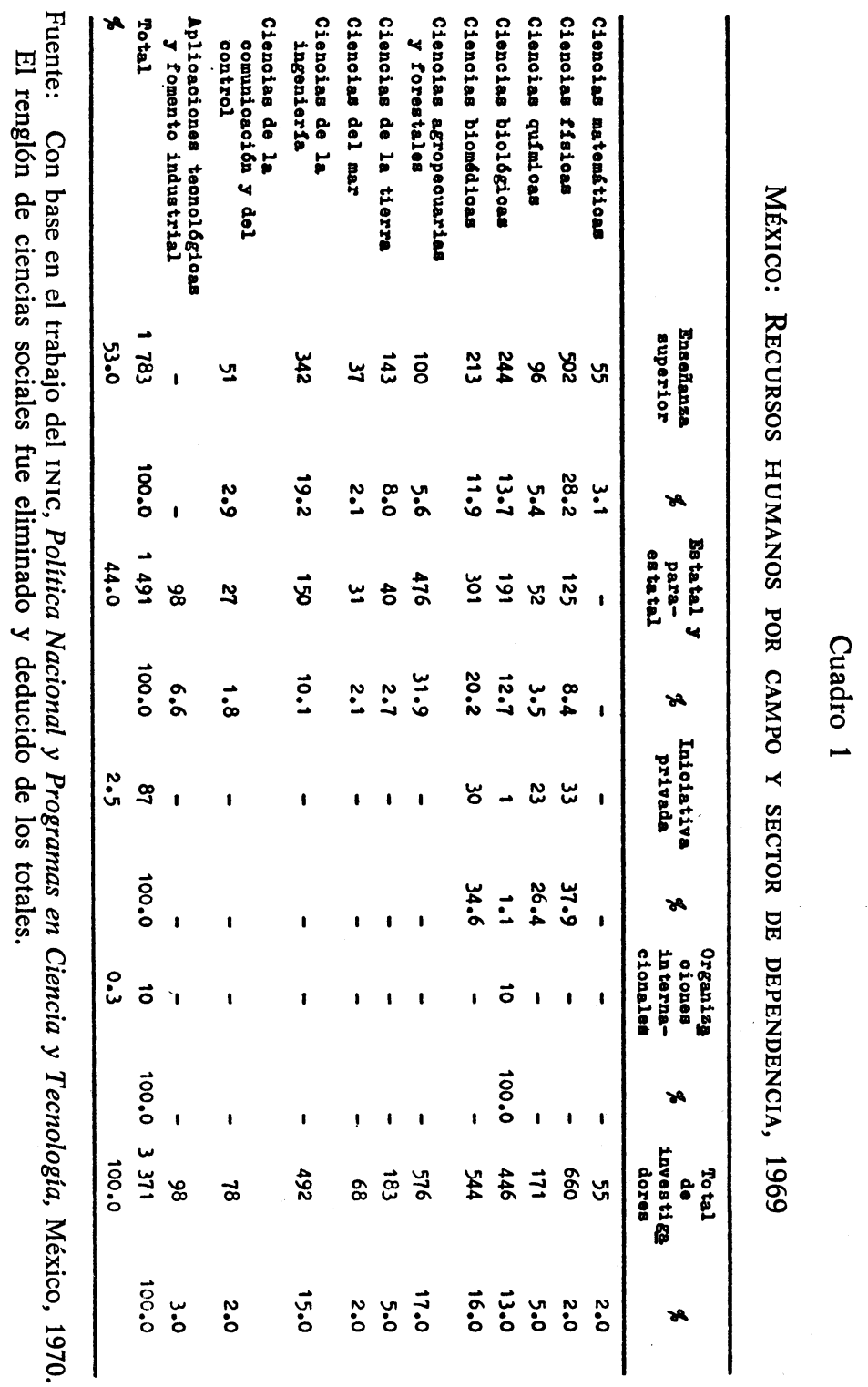


Cuadro 2

México: Recursos humanos POR CAMPo Y SECTOR DE DEPENDENCIA (Porcientos)

\begin{tabular}{|c|c|c|c|c|c|}
\hline & $\begin{array}{l}\text { Educaoion } \\
\text { superior }\end{array}$ & $\begin{array}{c}\text { Estatal y } \\
\text { paraestatal }\end{array}$ & $\begin{array}{l}\text { Inioiativa } \\
\text { privada }\end{array}$ & $\begin{array}{c}\text { Organismos } \\
\text { internacionales }\end{array}$ & $\begin{array}{c}\text { Total de } \\
\text { investigadores }\end{array}$ \\
\hline Cienoias matemátioas & 100.0 & - & - & - & 100.0 \\
\hline Cionolas Irsioas & 76.1 & 18.9 & 5.0 & - & 100.0 \\
\hline Cienoias qufmioas & 56.1 & 30.4 & 13.5 & - & 100.0 \\
\hline Cienoias biologicas & 54.7 & 42.8 & 0.3 & 2.2 & 100.0 \\
\hline Cionoias biomedioas & 39.2 & 55.3 & 5.5 & - & 100.0 \\
\hline $\begin{array}{l}\text { Cienoias agropecuarias } \\
\text { y foreatales }\end{array}$ & 17.4 & 82.6 & - & - & 100.0 \\
\hline Ciencial de la tierra & 78.1 & 21.9 & - & - & 100.0 \\
\hline Ciencias del mar & 54.4 & 45.6 & - & - & 100.0 \\
\hline $\begin{array}{l}\text { Cienolas de la } \\
\text { ingenterla }\end{array}$ & 69.5 & 30.5 & - & - & 100.0 \\
\hline $\begin{array}{l}\text { Cienolas de la } \\
\text { comunioaolón y del } \\
\text { oontrol }\end{array}$ & 65.4 & 34.6 & - & - & 100.0 \\
\hline $\begin{array}{l}\text { Apliosolonos teonologioas } \\
\mathrm{J} \text { fomento indus trial }\end{array}$ & - & 100.0 & - & - & 100.0 \\
\hline
\end{tabular}

Fuente: Con base en el cuadro 1.

plinario si se desea llegar a tener una visión de las estructuras profundas del objeto investigado. La "balkanización" de la ciencia no es otra cosa que el producto de una concepción parcial de los fenómenos: la "unificación" de la ciencia supone un enfoque crítico y no funcionalista en la IDE. La escasez de trabajos interdisciplinarios puede ser un indicador de que se adopte sistemáticamente una visión funcionalista de la actividad científica, intensificándose la dependencia frente al exterior.

\section{SERVicios de APOYo A LA IDE y DE VINCULACión CON EL APARATo PRODUCTIVO}

Los elementos de vinculación entre las actividades de IDE y el aparato productivo están en términos generales en vías de integración. La separación tradicional entre la IDE y la producción ha sido la causa de que estos elementos no existan sino en forma desordenada, algunos más desarrollados que otros.

Lo mismo se puede decir de los servicios de apoyo que requiere la IDE. El estudio del INIC señalaba ya el hecho de que existe un sistema desarticulado de información científica y técnica. ${ }^{24}$ Por otra parte, el mismo estudio señala que debido a la mala calidad técnica de las revistas científicas que existen en México, así como su mala presentación, producto de la carencia de recursos, se induce a los investigadores a depen-

24 INIC, op. cit., p. 59. 
der del extranjero tanto para publicar como para informarse acerca de los desarroilos en su especialidad (esta situación es también causa agravante y efecto de lo que se ha señalado en los dos puntos anteriores).

El levantamiento de cartas geológicas, de climas, edafológicas, sobre uso de suelos, así como un inventario de recursos naturales del país, son procesos que todavía están en sus etapas iniciales. Es importante el trabajo de la Comisión Nacional de Estudios del Territorio Nacional (CETENAL) en este sentido, pero su labor de ninguna manera ha concluido.

En cuanto a los servicios de información y documentación, los esfuerzos actuales por integrarlos, tanto por parte del Consejo Nacional de Ciencia y Tecnología (CONACYT) como la UNAM, son los primeros desde que dejó de existir en México el Centro de Documentación Científica y Técnica (CDCT). Este centro fue creado en 1954 como resultado de un acuerdo entre la Secretaría de Educación Pública y la UNESCo, pero desapareció seis años más tarde. Durante el decenio de los sesenta hubo intentos aislados de formar centros de información y documentación en diversas áreas; pero no es sino hasta 1971 con la creación del Centro de Información Científica y Humanística en la Universidad Nacional Autónoma de México (UNAM), y con la fundación del Servicio de Información Técnica (SIT) dentro del coNACYT, cuando se inicia un esfuerzo más integrado para dotar de este tipo de servicios al sistema científico y tecnológico.

El segundo de estos servicios se considera como el centro de lo que será el Sistema Nacional de Información. ${ }^{25}$ Dicho sistema estará integrado por servicios de información que ya funcionan o cuya integración está en proyecto. Estos servicios son: el Centro de Información del Sector Eléctrico (dependiente de la Comisión Federal de Electricidad pero constituido con ayuda y asesoría de CONACYT), el Centro Mexicano de Información Química (que deberá funcionar en los Laboratorios Nacionales de Fomento Industrial) y el Centro de Información Pecuaria (dependiente del Instituto Nacional de Investigaciones Pecuarias).

El Servicio de Información Técnica (SIT) está orientado hacia la pequeña y mediana industria y sus actividades principales son el servicio de enlace (visitas a empresas pequeñas y medianas para identificar requerimientos de información; hasta diciembre de 1973 se habían realizado 400 visitas que habían generado 170 preguntas sobre cuestiones técnicas y administrativas); servicio de preguntas y respuestas (que atiende solicitudes concretas de información: hasta diciembre de 1973 se habían contestado 865 preguntas de las que un $60 \%$ provenían de la industria; el sit atiende actualmente un promedio de 80 preguntas mensuales); publicación mensual del boletín de Noticias Técnicas, que se envía a 1300 suscriptores (se trata de un "servicio de alerta" que analiza más de 200 revistas técnicas en las industrias química, metalúrgica, cerámica y vidrio, farmacéutica, alimenticia, eléctrica y otras). El funcionamiento de estos

25 José Quevedo Procel, “Information System for Industrial Innovation: Practical Problems in Mexico", ponencia presentada en la Reunión Continental sobre la Ciencia y el Hombre. AAAS-Conacyt, México, junio de 1973, p. 4. 
servicios de información viene a llenar un vacío. Sin embargo, si la adquisición de experiencia era indispensable en un primer momento, ahora se requiere de una política clara que fije prioridades para los servicios de información. ${ }^{26}$

Sin embargo es claro que existen deficiencias que no requieren de un diagnóstico muy profundo para ser identificadas. Tal es el caso de la carencia de centros de información e investigación (así como en la enseñanza superior), y aun de servicios elementales de apoyo como bibliotecas. Las bibliotecas de trabajo en las principales universidades, con algunas excepciones, son muy deficientes. Un análisis sobre el desarrollo de nueve universidades en México, ${ }^{27}$ reveló graves deficiencias en los servicios de bibliotecas de los planteles examinados (el presupuesto anual promedio era de unos 16500 pesos, y el 70\% de las bibliotecas de las escuelas incluidas en el examen tenía menos de 2700 volúmenes). Estas deficiencias son más graves dada la carencia de recursos humanos calificados para atender estos servicios.

En cuanto a los servicios que deben servir de vínculo entre la IDE y la producción, destaca el hecho de que aunque el Servicio Nacional de Extensión Agrícola en teoría está orientado primordialmente hacia el pequeño agricultor y el ejidatario, éstos han recibido pocos beneficios de la IDE agrícola. Esto se debe en parte al tipo mismo de investigación que se lleva a cabo en este sector. ${ }^{28}$ Pero es importante el hecho de que el número de extensionistas agrícolas es claramente insuficiente: la proporción de agentes extensionistas en relación a familias campesinas es de aproximadamente 1:10 000..$^{29} \mathrm{El}$ extensionismo en el sector pecuario presenta todavía mayores defectos. Sus características particulares implican una estructura institucional diferente. Sin embargo, depende del Servicio Nacional de Extensión Agrícola, y la visita realizada al Instituto Nacional de Investigaciones Pecuarias reveló que no existía un vínculo estrecho entre este centro y la extensión pecuaria. En conclusión, el pequeño agricultor y el pequeño productor pecuario han estado marginados de los adelantos técnicos en materia de pastizales, alimentos balanceados, semillas mejoradas, y en general de mejores técnicas de cultivo. El impacto tecnológico en el sector agropecuario ha estado confinado a regiones bien delimitadas. En particular, la difusión de los conocimientos técnicos se ha mantenido concentrada en las zonas de influencia "directa" de los centros experimentales. Si bien no se ha evaluado el impacto en las zonas de influencia "indirecta" (o sea en aquellas en las que las condiciones ecológicas son semejantes) ésta parece que no ha sido notable. ${ }^{30}$

26 Sobre este punto véase el trabajo de Sergio Ortiz Hernán, "Servicios y actividades de apoyo al sistema de ciencia y tecnología”, México, 1973 (inédito).

27 Richard G. King, Alfonso Rangel Guerra y otros, Nueve universidades mexicanas, ANUIES, México 1972, p. 104. Las universidades incluidas aquí representan la mayor parte de la educación superior fuera del Distrito Federal.

28 Véase la nota 10.

29 En Estados Unidos y en Japón esta relación en 1969 era de 1:540 y 1:650 respectivamente.

30 Véase la nota 10. 


\section{SERVICIOS DE INGENIERÍA}

La ingeniería en México ha tenido un desarrollo variable. En algunas de sus ramas (por ejemplo, la ingeniería civil) el desarrollo ha sido importante y se ha efectuado paralelamente a la realización de importantes obras de infraestructura por parte del Estado. En otros campos, como la ingeniería de proyectos industriales (sobre todo en lo que se refiere a sus relaciones con procesos tecnológicos de carácter complejo), el desarrollo se encuentra en sus etapas iniciales.

La complejidad y ritmo del progreso técnico exigen en la actualidad un nuevo tipo de empresa y de organización (las firmas de ingeniería) que reúnen ingenieros y técnicos de diversas disciplinas para llevar a cabo de manera coordinada la concepción y realización de proyectos industriales de gran complejidad.

Las empresas de ingeniería, por su necesaria intervención en las diferentes fases de la ejecución de un proyecto industrial (estudios preliminares, selección de procesos y tecnologías, ingeniería básica y de detalle, selección y compra de equipo, etc.), representan un vínculo natural entre las actividades de la IDE, comercialización de tecnología, concepción y fabricación de equipo, etc. En un país en el que no existe una capacidad ingenieril propia, las empresas extranjeras constituyen uno de los canales más importantes de la transferencia de tecnología. Por lo tanto, es muy importante generar una capacidad ingenieril local con el objeto de lograr una mejor adecuación de la tecnología a las necesidades y características del país. En México las firmas privadas de ingeniería comenzaron a desarrollarse en el decenio de los cincuenta. Existían ya suficientes recursos humanos para iniciar estas actividades, pero hacía falta una organización cuyo modelo fue proporcionado en algunos casos por las empresas extranjeras que operaban en el país (en particular en la industria química). En otros casos la evolución misma de la demanda de servicios ingenieriles tuvo como resultados el surgimiento de empresas de ingeniería. Una firma actualmente en operación señaló que de ser inicialmente productora y vendedora de equipo pasó gradualmente a la instalación y a la prestación de un servicio de consultoría.

Después de un período inicial que se caracterizó por la especialización en la realización de proyectos industriales para la industria química, se está comenzando un proceso de diversificación y aun de exportación de servicios ingenieriles a Centro y Sud-América. La firma nacional más importante en México tiende ahora a diversificar sus actividades, participando en proyectos de construcción de unidades habitacionales, instalación de plantas para la industria automotriz y en la construcción de la primera planta nucleo-eléctrica del país. Entre las razones que explican esta diversificación se encuentra desde luego el hecho de que el mismo desarrollo industrial del país ha tenido como resultado una diversificación de la demanda de servicios ingenieriles; además las dimensiones del mercado en México no se prestan para la especialización 
excesiva; finalmente se considera que el proceso de formación de personal es muy caro y no resulta costeable despedir personal en caso de receso económico en alguna industria, por lo que se busca la manera de ocuparlo en otros proyectos.

En el ámbito del sector público, un caso interesante es el del Instituto Mexicano del Petróleo cuya organización (además de sus actividades de investigación y formación de recursos humanos) es equivalente a la de una verdadera empresa de ingeniería (subdirección de ingeniería de proyectos). La creación del Instituto Mexicano del Petróleo (IMP) en 1965 era indispensable para Petróleos Mexicanos (PEMEX) debido al crecimiento de sus necesidades científicas y técnicas y para conservar cierta independencia con relación a las empresas extranjeras de ingeniería así como de las firmas dueñas de los procesos.

La creación progresiva de una capacidad ingenieril propia del IMP, particularmente para la realización de proyectos en la industria petroquímica, responde a los objetivos siguientes: ${ }^{31}$

a) disminuir la salida de divisas ocasionadas por la compra de licencias, "know-how" y estudios de ingeniería;

b) desarrollar la formación de ingenieros y técnicos;

c) adaptar las normas y las especificaciones a las condiciones particulares de producción de México y a las capacidades de construcción de la industria nacional de bienes de equipo;

d) estandarizar los materiales de las instalaciones y utilizar de una manera más racional los equipos y los materiales disponibles.

Actualmente operan en México unas 10 o 12 empresas capaces de prestar servicios de consultoría, ingeniería de detalle, y en menor grado, de ingeniería básica. De esas firmas, tres o cuatro son totalmente nacionales.

El costo de la ingeniería en un proyecto industrial representa en promedio $10 \%$ del total. En consecuencia se calcula que entre 1971 y 1976 serán necesarios en el país servicios de ingeniería por más de 3000 millones de pesos. Se estima que la capacidad actual de las empresas consultoras permite generar proyectos por valor de más de 8000 millones de pesos al año, y por lo tanto podrá cubrir las necesidades locales, pero solamente respecto a la ingeniería de detalle. ${ }^{32}$ Como ha ocurrido hasta la fecha, la ingeniería básica tendrá que adquirirse en la mayoría de los casos en el extranjero. Esto se debe en parte a la falta de capacidad interna para generar la ingeniería básica y en parte a que en un gran número de casos el proveedor extranjero de la tecnología exige también ser el proveedor de la ingeniería básica. ${ }^{33}$ También influyen las restricciones que se incluyen en los créditos externos, que obligan al reci-

31 J. L. Fuentes, Revista del Instituto Mexicano del Petróleo, abril de 1970.

32 Datos presentados por Juan A. Zepeda Novelo en el Primer Congreso de la Asociación Nacional de Firmas de Ingeniería, 29 a 31 de marzo de 1971.

33 Reveladora de esta situación es la siguiente definición de lo que es la ingeniería básica: "se puede definir (la ingeniería básica) como lo hacen las com. 
piente a acudir tanto a productores de equipo como a proveedores de ingeniería básica.

Por otra parte, la oferta de servicios de ingeniería se encuentra altamente concentrada (la mayor de las empresas privadas nacionales domina en la actualidad unas dos terceras partes del mercado). Las empresas extranjeras se sienten atraídas ahora por el mercado mexicano y están adoptando la fórmula de asociarse a firmas nacionales ya sea en el ramo de la construcción de obras civiles o en el de la ingeniería industrial. De cualquier modo, en este último campo, los procesos y la ingeniería básica provienen en su mayor parte del extranjero.

Es evidente que la prestación de servicios de ingeniería está estrechamente vinculada con la inversión y la tecnología extranjera. Una empresa de ingeniería reveló que $80 \%$ de sus clientes eran empresas extranjeras que operan en México. Además, $90 \%$ de los servicios demandados se relacionaban con trabajos de ingeniería de detalle $(45 \%)$ y construcción y montaje $(45 \%)$; y solamente $5 \%$ se relacionaba con asesorías para la selección de tecnologías, lo que revela la poca importancia de esa empresa de ingeniería en la selección de técnicas (la misma firma reveló que no prestaba servicios en el campo de estudios de preinversión y planeación). Otra empresa proporcionó una lista de 160 proyectos en los que intervino: de ellos, 127 utilizaron tecnología extranjera, y aproximadamente $60 \%$ de los proyectos estaban relacionados con inversiones extranjeras directas. Finalmente, es importante tomar en cuenta que cuando un proyecto industrial incluye la adquisición de equipo o maquinaria en el extranjero, esto casi siempre implica alguna participación de empresas de ingeniería extranjeras.

En términos generales, existe poca vinculación entre las empresas de ingeniería y el sistema científico y tecnológico del país. Una de las empresas entrevistadas manifestó tener relaciones más bien informales con diversos centros de investigación. No hay indicios de que las empresas nacionales de ingeniería hayan servido como un enlace entre la producción y la realización de proyectos industriales por un lado y las actividades de IDE por el otro en forma generalizada.

Las empresas de ingeniería están agrupadas en una asociación nacional que tiene por objeto servir de canal de comunicación entre las diferentes unidades, así como contribuir a la solución de ciertos problemas generales que afectan el desarrollo de la ingeniería en México, tales como la normalización de la presentación de convenios, proyectos y contratos. En materia de contratación y ejecución de obras públicas ya existe un principio de reglamentación. ${ }^{34}$ Pero en los proyectos industriales, aunque

pañías licenciadoras: toda aquella información que permite asegurar un diseño tal que el proceso pueda ser garantizado". Ponencia sobre “Desarrollo vs. adquisición de tecnología", presentada por el Instituto Mexicano del Petróleo en la Mesa Redonda sobre "Experiencias en selección, adquisición, transferencia y adaptación de tecnología” (organizada por IMIQ, ANFI, AMIQ), México, octubre de 1973.

34 Ley de Inspección de Contratos y Obras Públicas, y Bases y Normas generales, publicadas en el Diario Oficial del 26 de enero, 1970. 
algunas empresas grandes utilizan formas estandarizadas para la presentación de los proyectos y contratos, no se ha hecho nada para resolver el complejo problema de su normalización para el conjunto de las firmas de ingeniería.

\section{IMPORTANCIA DEL SECTOR PÚBLICO Y SUS EFECTOS}

Otro rasgo que destaca es la preponderante participación del sector público en el desarrollo del sistema científico y tecnológico. A lo largo de su evolución, el SCT ha dependido de la acción del Estado tanto para su financiamiento como para su fomento y vinculación con el desarrollo de las fuerzas productivas. Por ejemplo, si bien no se puede precisar con exactitud el gasto total en IDE, sí se sabe que en su mayor parţe proviene del sector público (que incluye al subsector gobierno y al subsector paraestatal).

El financiamiento total se presenta en el cuadro 3.

\section{Cuadro 3}

México: Gasto total EN IDE

(Miles de pesos a precios corrientes)

\begin{tabular}{lcc}
\hline Año & Gasto total & \% del PIB \\
\hline 1964 & 155895 & 0.065 \\
1967 & 220000 & 0.070 \\
1968 & 274564 & 0.082 \\
1969 & 423380 & 0.120 \\
1971 & $723151^{a /}$ & 0.160 \\
1972 & 1015790 & 0.200 \\
1973 & 1350000 & $0.220^{b}$ \\
\hline
\end{tabular}

Fuente: Los datos fueron tomados de las siguientes obras: para 1964, Víctor L. Urquidi y Adrián Lajous, Educación superior, ciencia y tecnología en el desarrollo económico de México, El Colegio de México, 1967; el dato para 1967 proviene de una estimación de Víctor L. Urquidi en "Financiamiento de las actividades de investigación científica y tecnológica", ponencia presentada en la Reunión Nacional de Ciencia y Tecnología para el Desarrollo, México, 1967; el dato de 1968 proviene de un cálculo basado en las estimaciones de María Luisa Rodríguez Sala de Gomezgil, Las instituciones de investigación científica en México, UNAM, México, 1970 (se eliminaron los gastos en ciencias sociales); para 1969, Política nacional y programas de ciencia y tecnología, INIC, México, 1970; los datos de 1971 y 1972 corresponden a cálculos del Centro de Inversión y Asignación de Recursos del conaCYT, y el de 1973 corresponde a una estimación de la Dirección de Programación de. conacyt. Para estos tres años no fue posible eliminar el gasto en ciencias sociales por lo cual el cuadro no presenta una idea muy exacta del aumento del gasto en IDE durante 1971-1973.

a Los datos de 1971-1973 no incluyen el gasto que representa el presupuesto de CONACYT.

b Calculado en base a cifras preliminares del Banco de México. 
La parte correspondiente al sector público fue estimada en 1970 en $95 \% .{ }^{35}$ Pero en términos de los recursos humanos que dependían del sector público, $42.7 \%$ del total de investigadores, según el estudio del INIC, dependía del sector público (subsector gobierno y subsector paraestatal); el $52.8 \%$ dependía del sector enseñanza superior; y solamente $4.1 \%$ dependía del sector privado. ${ }^{36}$

Por otra parte, de acuerdo con ese diagnóstico, no existían investigadores dependientes del sector privado en las siguientes ramas: matemáticas, ciencias agropecuarias y forestales, ciencias de la tierra, ciencias del mar, ciencias de la ingeniería y ciencias de la comunicación y el control.

Esto es en parte consecuencia del papel tan importante del Estado en el origen y evolución del sistema científico en México. También es el resultado del tipo de desarrollo de las fuerzas productivas en el país y de la manera como se ha llevado a cabo el proceso de industrialización, el cual ha dependido básicamente de la tecnología extranjera. Pero si alrededor del sector público se ha llevado a cabo el esfuerzo primordial para el desarrollo de la ciencia y la tecnología, esto trae aparejados ciertos efectos no del todo benéficos.

En primer lugar, es posible que haya dado origen a ineficiencias en la administración de la investigación científica. La garantía de un presupuesto anual necesario para la realización de las investigaciones en un centro de IDE es sin duda indispensable; pero si no existen mecanismos de consulta internos en los institutos encargados de la investigación, y si por otra parte la toma de decisiones en esas instituciones está bastante centralizada es posible que exista un cierto desperdicio de recursos y una duplicación de esfuerzos. ${ }^{37}$

La información sobre la compra innecesaria de equipo muy costoso es difícil de obtener, pero sí existen suficientes datos aislados para concluir que la irracionalidad en la compra de equipo no es excepcional. En algunos centros visitados se declaró tener equipos subutilizados (hasta en $95 \%$ en un caso y $70 \%$ en otro). Por otro lado, la deficiente planeación que se lleva a cabo en muchos centros de IDE ha tenido como consecuencia la compra de equipo sin haber definido con precisión para qué sería utilizado o sin tener la capacidad (en términos de recursos humanos) para su adecuada utilización; y finalmente también han influido razones de prestigio. Destaca el hecho de que solamente en dos de los nueve centros visitados se señaló que la compra de equipo de investigación se llevaba a cabo previa convocatoria del mismo centro (lo

35 INIC, op. cit., p. 69.

36 Ibid., cuadro II, p. 346.

37 Durante la realización de las visitas a 9 centros de IDE, se recabaron datos sobre la existencia de "comisiones internas" de evaluación en algunos centros. Sin embargo, parece ser que en términos generales los mecanismos internos no favorecen por una parte la participación de los investigadores de base, y por otra no fomentan la crítica en la preparación del plan de trabajo de la institución típica de IDE. 
Cuadro 4

IMPORTACIONES DE APARATOS PARA OBSERVACIONES O DE ANÁLISIS (Miles de pesos)

\begin{tabular}{lccc}
\hline & 1968 & 1969 & 1970 \\
\hline Total & 203650 & 190687 & 281950 \\
$\begin{array}{l}\text { Como poroionto del total } \\
\text { de importaciones de bienes }\end{array}$ & 2 & & \\
de capital & 2 & 2 & 2.6 \\
\hline
\end{tabular}

Fuente: Banco Nacional de Comercio Exterior, Comercio Exterior de México, 1972; Dirección General de Estadística; Banco de México; La presentación de este cuadro se hace con fines ilustrativos. Es evidente que no todas las importaciones de equipo para observación o análisis se hace para actividades de IDE.

cual indica una iniciativa de la institución como respuesta a los planes internos de trabajo). En los casos restantes se señalaron como canales más importantes para la compra de equipo, los contactos personales con los proveedores y las publicaciones de éstos. ${ }^{\mathbf{3 8}}$ Además, algunas compras de equipo se han originado en créditos extranjeros (como en el caso del crédito inglés con el que el Departamento de Ciencias de Materiales del IPN compró equipo por más de 4 millones de pesos, incluyendo un microscopio electrónico, sin que se tuviera el personal para manejarlo).$^{39}$ En otro sentido, en varios de los centros visitados se señalaron problemas de tipo burocrático que dificultan la importación de equipo, por lo cual algunos programas de investigación se retrasan considerablemente.

Todavía no existe un inventario del equipo ya instalado en los centros de investigación, aunque ya se tiene uno que cubre a toda la UNAM como parte de un proyecto conjunto con el Consejo Nacional de Ciencia y Tecnología. La labor del Centro de Instrumentos (diseño y mantenimiento de equipo para la IDE y la enseñanza) es muy importante y en el futuro permitirá racionalizar la compra y uso de equipo para la investigación. Actualmente se contempla la posibilidad de comenzar a diseñar y producir equipo para la IDE y la enseñanza en una escala industrial (el Centro de Instrumentos se encuentra produciendo actualmente a una escala de prototipo). La importancia de este centro destaca si se considera que en promedio $95 \%$ del equipo instalado en los centros de investigación visitados resultó ser de origen extranjero. Además, el mantenimiento es proporcionado casi en su totalidad por los proveedores.

Existe una gran discrepancia en las cifras relativas a las importaciones de equipo científico debido a la diversidad de conceptos utilizados. Como se puede apreciar en el cuadro 4, dichas importaciones pueden conside-

38 Esto no siempre constituye un signo de irracionalidad dado que en ocasiones se conocen progresivamente los proveedores de equipo más idóneos para las actividades de un centro de IDE, ya sea a través de los contactos que se establecen o de las publicaciones que se reciben. Lo importante es si la política de adquisiciones se define en función de los requerimientos de los centros de investigación.

39 La negociación de estos créditos no ha sido analizada en México, pero no 
rarse modestas (por ejemplo, si se comparan con el total de las importaciones de bienes de capital) ; pero en términos del gasto total de IDE, probablemente su importancia sea mayor.

Además, las técnicas de administración del presupuesto son bastante inadecuadas tratándose de proyectos de IDE. Es raro el instituto de investigación que utiliza técnicas de programación plurianual del presupuesto con el fin de asegurar el financiamiento de los proyectos hasta su terminación. En los centros que dependen del sector público a nivel ministerial, el presupuesto global es aprobado anualmente. Esto dificulta la realización de los proyectos a largo plazo y reduce las posibilidades de movilidad interna de recursos de acuerdo con las prioridades de los centros. También se presenta el hecho de que los trámites burocráticos implican una tardanza que tiene como consecuencia una reducción efectiva del presupuesto. De los centros visitados, solamente dos utilizaban técnicas de presupuesto por programas (uno de ellos está financiado por el sector privado) . Se puede pensar que el problema se presenta en la gran mayoría de los centros de IDE que integran el SCT en México y que dependen del sector público. ${ }^{40}$

\section{LAS RELACIONES ENTRE EL SCT Y EL SISTEMA EDUCATIVO}

Institucionalmente, una gran parte del sistema científico y tecnológico se encuentra vinculado al sistema de enseñanza superior. De las 313 instituciones identificadas por el Centro de Diagnóstico del conACYT, 143 dependían directamente del sistema de enseñanza superior. Sin embargo, no existen relaciones estrechas entre la educación superior y el esfuerzo de investigación y desarrollo experimental. De hecho la contribución que realiza la IDE a la enseñanza superior es marginal (consiste primordialmente en el hecho de que existen investigadores que dedican parte de su tiempo a la docencia, lo cual no garantiza que el alumno participe en la IDE). La investigación académica es relativamente reducida, aunque no existen datos precisos sobre este punto. ${ }^{41}$ Pero en cambio sí existe evidencia de que sólo se lleva a cabo en los últimos años del ciclo de enseñanza superior, en los que se puede tener la posibilidad de participar en seminarios avanzados. El único estudio sobre México que examina este

es del todo raro en nuestro medio el que se otorguen créditos extranjeros a centros de IDE. Otro ejemplo de lo que se desea señalar es el préstamo de 400000 dólares por parte del Banco Interamericano de Desarrollo al Instituto Mexicano de Investigaciones Tecnológicas.

40 Véase el estudio del inIc y el cuadro del Centro de Diagnóstico del conacYT "Las instituciones de investigación en México" (inédito). Este último señala que de un total de 313 instituciones de investigación, $80 \%$ depende del sector público (aproximadamente unas 247). El trabajo incluye la investigación en ciencias sociales.

$41 \mathrm{La}$ investigación académica (también conocida como cuasi-investigación o investigación simulada) consiste básicamente en la "recreación" de investigaciones originales con el objeto de formar investigadores. 
punto, aunque sea de manera parcial ya que solamente cubre nueve universidades de provincia, parece confirmar lo anterior. ${ }^{42}$ En términos generales, no existen programas bien definidos que tengan por objeto lograr una contribución sistemática del esfuerzo de IDE a la enseñanza superior. Sin embargo, destacan algunos casos aislados en los que se ha tratado de vincular al alumno con problemas específicos de la investigación industrial y adaptación de tecnología. ${ }^{43}$

Por otra parte, los programas de estudio en la enseñanza superior no parecen orientar al alumno hacia la actividad de investigación, ni fomentar el espíritu crítico que aquélla presupone. Muchos de los defectos de que adolece la investigación científica en México son transmitidos a la enseñanza superior (las nociones de "prestigio", las preocupaciones por problemas ajenos a las necesidades del país, etc.) Además, la educación superior en México se enfrenta a sus propios problemas. Por ejemplo, al de una población escolar en continuo crecimiento. La matrícula total en el ciclo superior de la enseñanza media y la educación superior deberá crecer en el presente decenio a una tasa media anual del $13 \%$, de tal forma que de aproximadamente 320000 estudiantes en las universidades e instituciones de enseñanza superior en 1973-1974 se llegará a 405000 en 1975, y a 785000 en $1979-1980 .^{44}$

En forma simultánea, el sistema educativo se enfrenta a la necesidad de elevar las normas académicas por encima del nivel actual. Existen numerosos indicios de que el nivel de la enseñanza ha bajado en los últimos años. ${ }^{45}$

Considerando la magnitud y la complejidad del problema, el estudio de la Comisión Nacional de Planeamiento calcula que para 1975 el país

42 Véase Richard G. King, Alfonso Rangel Guerra y otros, op. cit. En particular la sección sobre investigación y desarrollo regional, pp. 30-36.

43 Véase el informe Appropriate Technology for Chemical Industries in Developing Countries, División de Estudios Superiores de la Facultad de Química, UNAM, México, 1972.

44 Véase el informe de la Comisión Nacional de Planeamiento Integral de la Educación, "La reforma educativa y el planeamiento integral de la educación en México", noviembre de 1970 (multigrafiado).

45 Un análisis del resultado de 42 exámenes presentados como requisito para la admisión a los programas de Maestría del Departamento de Química del Centro de Investigaciones y Estudios Avanzados del Instituto Politécnico Nacional, reveló recientemente un descenso en el nivel de preparación de los alumnos entre 1971 y 1974. La muestra es muy pequeña y las conclusiones del estudio no necesariamente son aplicables a otras ramas de la ciencia, pero el indicio es revelador y merece ser tomado en cuenta: véase Mauricio Shoijet, "Análisis de resultados de exámenes de admisión y la maestría en química en el cIEA del Instituto Politécnico Nacional en México (comparación del nivel de los estudiantes mexicanos con una nuestra de estudiantes norteamericanos)", México, 1974 (inédito). Véase también el proyecto del nuevo plan de estudios para la enseñanza superior en medicina en la UNAM: debido al crecimiento de la población estudiantil en esa disciplina, se pretende ahora que el estudiante tenga acceso a los hospitales solamente durante el último año de la carrera, en detrimento de su preparación. Véase Excélsior, marzo 19 de 1972, p. I-4. 


\section{Cuadro 5}

AlumNos MATRICULADOS Y EGRESADOS ${ }^{a}$ DE CURSOS DE POSGRADO Y SUPERTR PROFESIONAL DURANTE EL AÑO ESCOLAR, 1969-1970 Y 1970 b

\begin{tabular}{lcr}
\hline & Posgraduadosd & $\begin{array}{r}\text { Superior } \\
\text { profesional }\end{array}$ \\
\hline Entidades & & \\
Matrioulados & 141 & 103626 \\
\% & 25.0 & 47.4 \\
Egresados & 168 & 931 \\
\% & 14.9 & 43.4 \\
Distrito Foderal & & \\
Matrioulados & 4312 & 115019 \\
\% & 75.0 & 52.6 \\
Egresados & 958 & 12973 \\
Total & 85.1 & 56.6 \\
Matrioulados & & \\
\% & 5153 & 218637 \\
Egresados & 100.0 & 100.0 \\
\hline
\end{tabular}

Fuente: Jesús Barrón Toledo, "La educación superior en México, 1970", ANUIEs, México, 1970.

a Los que han aprobado todas las materias del plan de estudios y todavía no han presentado su examen profesional recepcional o final.

b Existen en un mismo año escolar dos tipos de calendario: A y B.

c Los estudios de posgrado son de especialización, a nivel de maestría o doctorado, teniendo como antecedente académico inmediato la licenciatura.

d Los estudios de superior profesional son los correspondientes a la licenciatura, teniendo como antecedente académico inmediato el bachillerato, la vocacional o estudios equivalentes. (Para este nivel trabajaron 116 instituciones superiores, con 369 facultades y escuelas.)

requiere destinar $78 \%$ más de lo que gastaba en educación en 1970 (a nivel de educación primaria, secundaria, media y superior), e incrementar esa cifra $82 \%$ entre ese año y 1980 . Lo anterior equivale más que a triplicar las erogaciones actuales en educación en el presente decenio, a precios constantes. ${ }^{46}$ No se pueden ignorar las implicaciones de lo anterior si consideramos que el sector público soporta el $85 \%$ del gasto en educación. $\mathrm{Si}$ se considera además que lo más conveniente es que se mantenga el nivel de esta participación, la capacidad de recaudación fiscal deberá aumentarse o en todo caso la proporción del gasto público destinado a la educación deberá aumentar $25 \%$ a $30 \%$ aproximadamente.

La concentración de la educación superior en el Distrito Federal es indudablemente uno de los factores que agrava los problemas que aquejan el sistema educativo del país. Como se puede observar en el cuadro 5, dicha concentración alcanza proporciones realmente alarmantes.

46 Comisión Nacional de Planeamiento Integral de la Educación, op. cit., p. 40. A precios de 1960, el gasto total en educación alcanzó en 1970 la cifra de 8740 millones de pesos; en 1975 debería llegar a los 15530 millones; y en 1980 a unos 28320 millones de pesos. El gasto pasaría así del $3 \%$ del PIB al 3.8 en 1975 y $5 \%$ en 1980 . 
Además, los servicios de infraestructura del sistema educativo deberán modernizarse e incrementarse. Ya se ha mencionado el resultado del estudio sobre nueve universidades en México y las conclusiones del informe del INIC ${ }^{47}$ en relación a las deficiencias y carencias de los sistemas de apoyo con que cuentan actualmente el SCT y la enseñanza superior. Si el sistema educativo desea comenzar a elevar los niveles de la enseñanza media y superior, se requiere realizar un esfuerzo en el sentido de mejorar la relación alumnos/maestros, ampliar instalaciones, así como mejorar las técnicas de enseñanza. ${ }^{48}$ En cuanto a las técnicas de enseñanza, actualmente se lleva a cabo un esfuerzo incipiente para dotar de instrumentos de enseñanza a los ciclos medio y superior de la educación en México. ${ }^{49}$

Por otra parte, es necesario proceder a una revisión y actualización de los planes de estudio. El estudio del INIC señalaba que en algunas instituciones de enseñanza superior existían "retrasos" de 5 a 10 años en los planes de estudio con relación a instituciones "avanzadas" en otros países. $^{50}$ La terminología empleada en ese estudio revela la existencia de una concepción lineal de lo que es el proceso de desarrollo. Sin embargo, el problema no consiste simplemente en la presencia de un atraso con respecto a nuevos desarrollos en la ciencia. El problema se complica si se toma en cuenta que los programas de estudio no orientan al estudiante hacia la investigación ni fomentan una apreciación crítica de la problemática que se le presenta a lo largo de sus estudios. Normalmente los planes de estudio buscan formar al estudiante para que ocupe un puesto en una estructura económica bien determinada: se "producen" así técnicos y profesionistas para el aparato productivo. Cuando se trata de modificaciones al plan de estudios, éstas consisten en simples adiciones a lo ya existente pero sigue siendo el "mercado" de profesionistas el que determina fundamentalmente el contenido de dichos planes. El mercado de trabajo se mueve a ritmos diferentes tratándose de la creación de empleos de diferentes niveles de escolaridad. Los datos más recientes revelan que la creación de plazas de trabajo para personas que han cursado estudios universitarios es casi tres veces más rápida (155\% en el decenio 1960-1970) que la creación de nuevas plazas para personas sin escolaridad $(56 \%) .^{51}$

47 Véanse las notas 24 y 27.

48 Sobre este punto consúltese el estudio de Noel F. McGinn, Russell Davis y Richard G. King, The Technology of Instruction in Mexican Universities, Education and World Affairs, Nueva York, 1968. El estudio se realizó en colaboración con la Asociación Nacional de Universidades e Institutos de Enseñanza Superior (ANUIES) y la Graduate School of Education de la Universidad Harvard. Entre las conclusiones se menciona que las escuelas y facultades visitadas carecían de instrumentos y aparatos auxiliares para la enseñanza; también se destaca el estado deficiente de las bibliotecas en la gran mayoría de los planteles estudiados.

49 Se trata básicamente del proyecto de la ANUies y el Centro de Instrumentos de la UNAM, para la producción (a una escala todavía muy reducida) de instrumentos y equipo para la enseñanza media y superior.

50 INIC., op. cit., p. 81.

51 Rodrigo A. Medellín y Carlos Muñoz Izquierdo, "La nueva Ley Federal de educación ante la problemática educativa y social de México", Centro de Estu- 
Esta situación agrava la disparidad de oportunidades en perjuicio de los estratos sociales de menores ingresos a través de una "devaluación" del valor de la educación recibida (como medio para obtener empleo). Además, es evidente que un gran número de plazas a nivel medio se están cubriendo con fuerza de trabajo de mayor escolaridad que la requerida, debido a las deficiencias en la educación técnica. ${ }^{52}$

Los defectos en el sistema de la enseñanza superior son producto de una gran variedad de factores íntimamente relacionados. Pero sin un mecanismo que permita la planeación de la educación, no se podrán evitar males como la gran concentración de alumnos en pocas instituciones (aproximadamente $51 \%$ del total de alumnos en la enseñanza superior se encuentra matriculado en la Universidad Nacional y el Instituto Politécnico Nacional), ni la concentración de alumnos en ciertas disciplinas tradicionalmente privilegiadas que cuentan con un cierto grado de desarrollo y con un mayor número de profesionales, en detrimento de otras disciplinas necesarias para el desarrollo industrial, científico y tecnológico del país.

En 1959, la proporción de la población escolar en carreras relacionadas con la industria manufacturera era equivalente al $15.1 \%$ de 69930 estudiantes en instituciones de enseñanza superior; en 1967, esa proporción era de $16.1 \%$ de un total de 144937 estudiantes a nivel superior. ${ }^{53}$ Desde entonces, esta proporción no ha aumentado de manera significativa.

\section{LAS FUNCIONES DE COORDINACIÓN Y FOMENTO DE LA IDE}

Muchos de los defectos del sistema científico-tecnológico se agravaron por el hecho de que hasta 1971 no existía en México un organismo responsable de formular y ejecutar una política en ciencia y tecnología. El alto grado de concentración geográfica de los centros de investigación, por ejemplo, es uno de esos defectos. Cerca del $70 \%$ de las instituciones de IDE se encuentran localizadas en el Distrito Federal (205 instituciones frente a 108 en las entidades).$^{54}$ La concentración de recursos también se revela a nivel institucional: aproximadamente $30 \%$ de los recursos humanos en la IDE trabaja en la Universidad Nacional; $50 \%$ de las citas de investigación científica que hacen referencia al trabajo realizado en México corresponden a investigaciones efectuadas en la Universidad; y

dios Educativos, Serie de publicaciones eventuales, Núm. 2, México, 1974, pp. 45-76. Véase también el artículo de Pablo Latapí, "Expansión educativa y desempleo", Excélsior, febrero 2 de 1974.

52 A pesar de la creación de nuevos centros de capacitación a ese nivel, todavía queda mucho por hacer. Véase Gloria González Salazar, Los problemas de la mano de obra en México, unAM, México, 1970.

53 Adrián Lajous Vargas, "Aspectos de la educación superior y el empleo de profesionistas en México”, El Colegio de México, 1969.

54 Véase el cuadro ya citado del Centro de Diagnóstico de conAcyt, "Las instituciones de investigación en México”. 
de 2000 proyectos de IDE en ejecución en México en 1970, 44\% se realizaba en dicha institución. ${ }^{55}$

Es cierto que desde 1935 existían organismos encargados de coordinar y fomentar las actividades de IDE, ${ }^{56}$ pero su acción se limitó a conceder cantidades más o menos reducidas de becas y ayudar al desarrollo de algunos proyectos de investigación. El Instituto Nacional de la Investigación Científica (INIC) en 1970 contaba con un presupuesto de apenas 7 millones de pesos, de los cuales aproximadamente 5 se destinaban al pago de becas.

Entre 1969 y 1970 y por iniciativa de varios representantes de centros de investigación y enseñanza superior, así como del INIC, se llevó a cabo un estudio sobre el desarrollo científico-tecnológico y la política científica en México. La conclusión más importante del estudio es sin duda la que se refiere a la necesidad de establecer un organismo encargado de formular y ejecutar esta política. ${ }^{57}$

Así se creó en 1971 el Consejo Nacional de Ciencia y Tecnología (CONACYT) con funciones que básicamente pueden ser agrupadas en dos categorías: a) funciones de asesoría al Ejecutivo Federal, en las que la responsabilidad principal de la acción no recae sobre el CONACYT; y b) funciones auxiliares, en las que el Consejo ya tiene una responsabilidad directa por delegación del ejecutivo. ${ }^{58}$ Entre otras atribuciones del Consejo, su ley orgánica incluye las siguientes:

a) asesorar al Gobierno Federal para la formulación de una política nacional en ciencia y tecnología;

b) coadyuvar al fortalecimiento de la infraestructura científica y tecnológica nacional;

c) formular programas indicativos de ciencia y tecnología para orientar las actividades de investigación hacia la solución de problemas del desarrollo económico y social; y

d) promover y canalizar la cooperación internacional hacia programas que interesen en forma prioritaria al país.

55 Guillermo Soberón y Arcadio Póveda, "Mexico's Science and Technology Gap and the Program for Scientific Development of the UNAM", ponencia presentada en el simposio sobre "The Science and Technology Gap in Latin America", Universidad de Nebraska, abril de 1972.

56 El Consejo Nacional de la Educación Superior y de la Investigación Científica creado en 1935, fue reformado en 1942 y se convirtió en la Comisión Impulsora y Coordinadora de la Investigación Científica. En 1950 se convirtió en el instituto Nacional de la Investigación Científica.

57 Sin embargo, muchas de las recomendaciones del estudio del INIC no fueron recogidas en la creación del conACYT: por ejemplo la integración de los comités para la determinación de necesidades de IDE, o la propuesta para la creación de la comisión de financiamiento.

58 Esta sección se basa en los trabajos inéditos de Sergio Ortiz Hernán, Federico Torres Arroyo y Alejandro Nadal, "Análisis de las funciones del Consejo Nacional de Ciencia y Tecnología”, México 1973; y de Mauricio Campos y Alejandro Nadal, "Notas para el examen de la actuación del conAcyT en sus primeros dos años de existencia”, México, diciembre de 1972. 
La ley constitutiva del CONACYT adolece de serios defectos en su estructura y redacción. ${ }^{59}$ Estos defectos han provocado que la acción del Consejo sea difícil de organizar y que se carezca de instrumentos y mecanismos de ejecución. La falta de experiencia que sobre el tema de política científica se tenía en México, así como el crecimiento desproporcionado del personal del CONACYT durante sus primeros dos años de existencia, limitaron bastante la acción de este organismo e impidieron el que se estableciera una adecuada vinculación con el resto del sistema científicotecnológico. ${ }^{60}$ Actualmente, el conACYT está en un período de reformulación de sus objetivos tomando en cuenta las atribuciones que le concede su ley orgánica y las conclusiones de una auditoría técnico-administrativa solicitada por el propio Consejo a la Secretaría de la Presidencia. Las conclusiones de este estudio señalan que numerosos problemas que enfrenta el CONACYT se deben a la falta de una concepción clara de las funciones encomendadas al Consejo. ${ }^{61}$ De la labor de reformulación de objetivos destacan las siguientes definiciones: ${ }^{62}$

a) el CONACYT no debe realizar investigaciones en forma directa;

b) el CONACYT es una parte muy importante del sistema científicotecnológico pero no constituye la totalidad de ese sistema;

c) La tarea fundamental es la de coordinar acciones.

Sin embargo, subsisten los problemas de la ley constitutiva. En cuanto al primer tipo de funciones asignadas al Consejo, o sea las de asesoría, prácticamente cubren todo el espectro de actividades de IDE, así como los servicios de infraestructura y apoyo, actividades técnicas, importación de tecnología, formación de recursos humanos y desde luego, todas aquellas actividades de dirección, administración y financiamiento de la IDE y formación de recursos humanos. Sin embargo la ley no define los mecanismos que quedarían al alcance del conACYT para llevar a cabo esa función de asesor del Ejecutivo Federal en materia de política científica y tecnológica.

En relación a las funciones que con carácter auxiliar se asignan, no es uniforme la manera como incide la labor del Consejo sobre el espectro de las actividades científico-tecnológicas ni por el tipo de acciones que la ley encarga a este organismo. Por ejemplo, toda la gama de actividades técnicas que sirven de vínculo entre la IDE y la producción (di-

59 Por ejemplo, el artículo 2 de la Ley que crea el Consejo Nacional de Ciencia y Tecnología, contiene en 27 fracciones las funciones del Consejo: desde detalles como la comunicación entre el Consejo y sus becarios hasta generalidades sobre las funciones de asesoría. Véase la Ley que crea el Consejo Nacional de Ciencia y Tecnología, Diario Oficial, Núm. 47, 29 de diciembre de 1970.

60 Algunos de estos problemas se mencionan en el "Estudio de Organización del CONACYT" elaborado por la Secretaría de la Presidencia en 1973. Sin embargo se dejaron de lado los problemas principales relacionados con la planeación en ciencia y tecnología, así como la vinculación con la comunidad científica.

61 Gerardo Bueno Zirión, "Atribuciones, estructura y programas del CoNACYT", CONACYT (serie documentos), México, 1974, p. 4.

62 Ibid. 
seño ingenieril, operaciones de montaje de plantas industriales, asistencia técnica, etc.) están prácticamente desatendidas por la ley del cONACYT. Además, por lo que toca a las fases de elaboración, ejecución y evaluación de una política científica y tecnológica, en términos generales se le otorgan facultades al CONACYT en cuanto a la ejecución, pero entendida ésta en términos de actividades de promoción y fomento. Las fases de fijación y evaluación de la política científica se encuentran cubiertas de manera muy deficiente. En conclusión, en los casos en que la ley otorga funciones concretas al Consejo, los mecanismos son bastante deficientes o incompletos.

Entre los mecanismos destacan los programas indicativos de investigación que el consejo tiene encomendado estructurar. En los primeros dos años se intentó diseñar una metodología para el funcionamiento de dichos programas. ${ }^{63}$ Pero cuando se decidió suprimir el Centro de Planeación y Programas Indicativos en septiembre de 1972, aduciendo que su existencia "implicaba la concentración en una sola dependencia de las funciones de planificación y coordinación", ${ }^{64}$ se nulificaron las posibilidades de seguir definiendo los programas indicativos y de adquirir experiencia. Los problemas mencionados condujeron a que solamente funcionara un programa indicativo (sobre alimentación), quedando una lista de temas como simples proyectos. La situación ha evolucionado rápidamente en los últimos meses tanto desde el punto de vista de la metodología, ${ }^{65}$ como en el apoyo a los programas indicativos que son en realidad el principal mecanismo al alcance del Consejo. En la actualidad, esos programas se consideran como la primera etapa en la instrumentación de la planeación de la actividad científica y tecnológica. Ya se han definido los siguientes temas para la iniciación de los programas indicativos correspondientes: salud, vivienda, demografía, energéticos, aprovechamiento de recursos marinos, ecología tropical, apoyo técnico a la investigación industrial y otros. ${ }^{66}$

Por otra parte, la ley faculta al Consejo para canalizar recursos adicionales hacia las instituciones académicas o centros de investigación para el fomento y realización de investigaciones en función de programas y proyectos específicos "sin perjuicio de que dichas instituciones y centros sigan manejando e incrementando sus propios fondos". ${ }^{67}$ Recientemente el CONACYT ha definido su política respecto a la canalización de recursos adicionales como sigue: "El CONACYT debe apoyar la investigación científica y tecnológica canalizando recursos adicionales, pero no puede constituir la principal fuente de recursos dentro del sistema. Se trata de que

63 Véase Centro de Planeación y Programas Indicativos, Conacyt, "La planeación y los programas indicativos en la ciencia y la tecnología”, México, julio de 1972 (mimeografiado).

64 Conacyt, II Informe de Labores del Director General de la Junta Directiva, México, marzo de 1973, p. 2.

65 Véase Dirección de Programación, conacyT "Aspectos generales de los programas indicativos del conACYT", agosto de 1973 (inédito).

66 Gerardo Bueno Zirión, op. cit., p. 17.

67 Artículo 12, fracción VII, Ley que crea el conacYT. 
Cuadro 6

Presupuestos del CONACYT

(Miles de pesos a precios corrientes)

\begin{tabular}{lcc}
\hline$\Delta$ ño & Importe & $\begin{array}{c}\text { \% del gasto } \\
\text { total on IDE }\end{array}$ \\
\hline 1971 & 51068 & 6.9 \\
1972 & 108909 & 10.7 \\
1973 & 156600 & 11.6 \\
\hline
\end{tabular}

Fuente: Estimación de la Dirección de Programación, conacyt, y II Informe del Director General del Consejo y la Junta Directiva. Las estimaciones del gasto total en IDE para 1971 a 1973 incluyen la investigación en ciencias sociales.

el Consejo tenga en este aspecto una participación relativamente reducida, ya que lo importante es que actúe sobre el sistema fundamentalmente vía la formulación de planes y programas... orientando y no centralizando los esfuerzos del país en materia de ciencia y tecnología". ${ }^{68}$

En función de lo anterior el Consejo estima conveniente que la mayor parte de los recursos que el Estado destina a la investigación sean canalizados directamente por él mismo a las instituciones y que sólo una proporción reducida (entre $11 \%$ y $15 \%$ ) sea concedido vía el CONACYT. La finalidad es canalizar esos recursos hacia puntos estratégicos y orientar de esta manera las actividades del sistema científico y tecnológico.

Sin embargo, de acuerdo con las estimaciones de la Dirección de Programación del propio Consejo, el presupuesto total del CONACYT representaría apenas $6.9 \%$ del gasto total en IDE en 1971, $10.7 \%$ en 1972 y $11.6 \%$ en $1973 .{ }^{69}$ Esto no quiere decir que todo el gasto del Consejo se destine a la IDE. Entre 1971 y 1973 los gastos de funcionamiento de este crganismo han representado aproximadamente $57 \%$ del presupuesto anual, con lo cual se reduce más la influencia que puede tener el CONACYT para orientar las líneas de investigación hacia los "objetivos" del desarrollo. ${ }^{70}$ Para 1974 se prevé que la proporción que representa el programa de canalización de fondos al SCT será equivalente al $33.7 \%$ del presupuesto del CONACYT (en 1973 fue el 24.9\%; véase el cuadro 6).

$\mathrm{La}$ interrogante que se puede plantear con respecto a esta política es si efectivamente se puede orientar el desarrollo de nuevas investigaciones hacia los "objetivos del desarrollo nacional" como la ley señala, con un

68 Gerardo Bueno Z., op. cit., p. 10.

69 Las estimaciones del Centro de Inversión y Asignación de Recursos indican para 1973 una participación mayor dentro del gasto total en IDE (16.7\%), pero en todo caso sigue siendo una participación marginal.

70 Dato proporcionado por la Dirección de Programación. Por otra parte, la canalización de recursos no siempre ha sido bien orientada y hubo una falta de criterios. Por ejemplo, hasta julio de 1973 más del $70 \%$ de los proyectos aprobados estaban dentro del área biomédica-bioquímica (véase el documento "Notas para integrar un plan de acción inmediata del Consejo”, Centro de Inversión y Asignación de Recursos, conacyt, México, 1973). 
volumen de recursos adicionales que representa una proporción reducida del total de recursos destinados a la investigación. Es posible que para equilibrar esta participación reducida se requiera una intervención por parte del Consejo en la asignación de fondos por parte del Estado a los centros de IDE así como en la definición de los proyectos para los cuales están destinados esos fondos.

Esta interrogante se justifica si se considera que el sct de México se acerca a lo que Alexander King llama el "modelo pluralista"; $;$ " en el que las decisiones relacionadas con ciencia y tecnología son tomadas en forma aislada por departamentos y agencias diferentes bajo una supervisión general de la Secretaría de Hacienda o del Patrimonio Nacional.

En conclusión, los diferentes centros e institutos que operan en México constituyen centros de decisión más o menos autónomos. En principio se podría pensar que siendo el sector público quien financia en un $95 \%$ el funcionamiento del sistema científico, no debiera existir ningún obstáculo para reorientar la IDE. Sin embargo, la situación es más compleja: intereses creados, control ministerial sobre algunos centros de IDE, la importante cuestión de la autonomía universitaria son todos factores que dificultan esta tarea.

\section{LA IMPORTACIÓN DE CONOCIMIENTOS TÉCNICOS}

Las importaciones de conocimientos realizados por el aparato productivo no son filtradas por el sistema científico-tecnológico nacional. Esto trae aparejada una serie de graves consecuencias en la búsqueda, identificación, selección, negociación y adquisición de la tecnología extranjera. Para comprender cabalmente la situación en la que se encuentra el SCT nacional, es importante examinar brevemente el proceso de importación de tecnología (este examen se limita al flujo de tecnología importada vía acuerdos contractuales).

El grueso de los conocimientos técnicos utilizados por el aparato económico proviene de fuentes externas debido a varias razones. En primer lugar, de acuerdo con su evolución histórica el proceso de desarrollo de las fuerzas productivas estuvo condicionado a no requerir sino conocimientos técnicos de origen extranjero ( $\mathrm{y}$ solamente en las ramas que se consideraba de interés desarrollar, por ejemplo, la minería). Posteriormente, el subdesarrollo del sistema científico y tecnológico, debilitado por la falta de vinculación con la producción, se reveló incapaz de satisfacer la demanda potencial de conocimientos técnicos que el crecimiento económico plantea. La inversión extranjera directa trajo aparejada una cierta tecnología que no era posible obtener localmente, pero la no utilización de los servicios locales debilitó más todavía el sCT. Además, el proceso de sustitución de importaciones solamente hizo explícita una de-

71 Véase el documento "A Science Policy for Canada", Report of the Senate Special Committee on Science Policy", volumen 3 ("A Government Organization for the Seventies"), p. 617. 
manda de tecnología extranjera que anteriormente estaba incorporada en los bienes importados.

Finalmente, el aparato productivo ha sido inducido a importar conocimientos técnicos por la acción de diversos mecanismos relativos a la política de fomento industrial.

En sí, las importaciones de conocimientos técnicos no representan un peligro para un país (en términos de mayor dependencia) siempre y cuando se realicen bajo un régimen de orientación y control en cuanto a su búsqueda, selección, negociación y su adquisición y adaptación. Como se explica más adelante, en México el régimen de control existe, aunque de manera incompleta, en relación con algunas de estas fases del proceso de transferencia internacional de tecnología.

En cuanto a la orientación del proceso de importación de conocimientos técnicos, se puede afirmar que dicho régimen es todavía muy incipiente y que la importación se lleva a cabo de manera indiscriminada y no selectiva. Así se explica que el flujo de conocimientos importados no pase por las diferentes unidades del SCT nacional para su evaluación y adaptación. No existe un estudio detallado sobre este punto, pero en términos generales se puede señalar que los centros de IDE realizan muy pocos trabajos de adaptación de tecnologías extranjeras al medio mexicano, ya se trate de adaptaciones con respecto al tamaño del mercado o a la proporción de factores de producción. En este sentido es interesante observar que durante las entrevistas con los directivos de los nueve centros de investigación se pudo comprobar que los trabajos relacionados con operaciones de transferencia internacional de tecnología representa un volumen muy reducido de las actividades de esas instituciones. Sin pretender generalizar este dato a todo el SCT, la información recabada parece indicar que los centros de IDE intervienen muy poco en la selección y adaptación de tecnologías. En algunos casos se realizan adaptaciones menores (por ejemplo, a condiciones de presión, temperatura y humedad o a las características de las materias primas y otros insumos nacionales). También es probable que se lleve a cabo un volumen ínfimo de trabajos mayores de adaptación, ya sea al tamaño del mercado, a la proporción de factores o a la dotación de recursos naturales. ${ }^{73}$

La actitud del sector privado es importante para comprender el pro-

72 En este sentido, véase el resultado de dos encuestas sobre algunas ramas industriales, en particular para la industria químico-farmacéutica, en Mauricio de María y Campos, "Transferencia de tecnología, dependencia del exterior y desarrollo económico", UNAM, Escuela Nacional de Economía (tesis profesional) México, 1968; y Gerardo Bueno, Jorge Eduardo Navarrete y Miguel S. Wionczek, "La transferencia internacional de tecnología a nivel de empresa: el caso de México", trabajo preparado para la División de Hacienda Pública de la onU, México, 1971.

73 En este sentido es revelador el hecho de que uno de los dos centros de investigaciones tecnológicas para la industria que declararon realizar trabajos de adaptación de tecnologías señaló que lo hacía en muy pocos casos y que consideraba a la actividad de adaptación a la escala del mercado como "sumamente difícil". El otro centro señaló que solamente entre 15 a $20 \%$ de sus trabajos eran asesorías para la selección de tecnologías. 
ceso de transferencia de tecnología. A pesar de que faltan estudios de carácter empírico que traten específicamente el tema de la "demanda" de tecnología por el sistema productivo mexicano, es evidente que la demanda hacia fuentes locales continúa siendo muy débil, y en lo fundamental, sigue orientada hacia el extranjero. Las causas de lo anterior son muy variadas: básicamente se trata de una consecuencia del subdesarrollo dependiente de las fuerzas productivas, ${ }^{74}$ pero ahora también es un factor importante la actitud del empresario mexicano. Una encuesta realizada en 1970 mostró que sólo 10 de 71 empresas entrevistadas consideraron que la inexistencia de la IDE era un obstáculo al desarrollo. ${ }^{75}$ En 1968, otra cncuesta reveló que ni siquiera existía en el sector empresarial un concepto claro de lo que es la actividad de investigación industrial: una proporción muy alta de las empresas que respondió afirmativamente a la pregunta sobre la realización de actividades de IDE, identificó con ese concepto actividades tales como control de calidad y estudios de mercado. ${ }^{76}$

Es importante indicar que existen diferencias importantes en el proceso de adquisición de tecnología tratándose de empresas nacionales (generalmente con poco poder de negociación), de subsidiarias extranjeras (las decisiones importantes se toman en la casa matriz), de empresas conjuntas (las decisiones se toman de acuerdo con el socio dominante, en general la parte extranjera) o de empresas del Estado (con una mayor capacidad tecnológica que en principio debería proporcionar una mayor libertad para diversificar fuentes de tecnología, pero que en muchos casos se ve contrarrestada por el creciente uso de financiamiento externo).$^{\mathbf{7 7}}$

La escasa capacidad tecnológica de la industria nacional se revela tanto en su aversión al riesgo (y por lo tanto a la realización de actividades de IDE), como en su vinculación tecnológica con el exterior. Normalmente, el SCT no interviene en la selección de tecnologías extranjeras, y el empresario concluye todo tipo de arreglos contractuales para la importación de conocimientos técnicos (patentados o sin patentar). En términos generales se puede concluir que la importación de conocimientos ha sido irracional desde varios puntos de vista, lo cual se refleja en los costos que han representado para el país dichas importaciones. Normalmente, la importación de tecnología se realiza sin ningún criterio social, macroeconómico, o aún ecológico. En conclusión, la irracionalidad en la compra de tecnología foránea se deriva fundamentalmente de cuatro causas:

a) la acción de diversos mecanismos de política económica que siguen orientando la demanda de tecnología hacia fuentes externas; ${ }^{78}$

74 Este aspecto aparece en un trabajo inédito de los mismos autores.

75 Flavia Derossi, The Mexican Entrepreneur, OECD Development Center, París, 1970.

76 Mauricio de María y Campos, op. cit.

77 Véase a Miguel S. Wionczek, "La transferencia de tecnología en el marco de industrialización mexicana", en M. S. Wionczek (Comp.) Comercio de tecnología y subdesarrollo económico, UNAM, México, 1973, pp. 250-254).

78 Por ejemplo, la acción de la Regla XIV que facilita la compra en el exterior de bienes de capital, y aún los Programas de Fabricación que maneja la Secre- 
b) la escasa capacidad tecnológica de la empresa típica y la escasa utilización de unidades del SCT para buscar y comprar tecnología anulan casi totalmente la capacidad de negociación de las empresas compradoras; ${ }^{79}$

c) la carencia de una política selectiva en materia de inversiones que se traduce en una compra indiscriminada de tecnología aun para sectores de muy dudosa relevancia para el esfuerzo nacional de desarrollo (por ejemplo para la industria de cosméticos); ${ }^{80}$

d) la bajísima propensión del industrial mexicano a correr riesgos lo induce a buscar y adquirir tecnologías "seguras y comprobadas" en el exterior. ${ }^{81}$

El costo de la transferencia de tecnología ha sido exagerado como consecuencia de lo anterior. En términos de costos explícitos que representan un flujo financiero, existen diferentes cálculos sobre el monto de los pagos por concepto de regalías sobre el uso y explotación de patentes y asistencia técnica. Una idea de los pagos que se realizan en México, por país recipiente y por rama industrial la proporciona el estudio de la Secretaría de Hacienda, que en 1969 examinó la información sobre los pagos que diversas empresas hacían al exterior por concepto de asistencia técnica. ${ }^{8 \cdot 2}$

taría de Industria y Comercio para promover la integración vertical de procesos industriales a través de la producción local de insumos importados. Este último mecanismo posiblemente tiene el efecto de aumentar la demanda de tecnología extranjera para la producción de bienes intermedios en los sectores que se acogen a los beneficios de dichos programas.

79 La capacidad de negociación del comprador es de por sí muy poca en el caso del mercado de tecnología, debido en términos generales al hecho fundamental de que es muy difícil evaluar los conocimientos que se desea adquirir, ya que se requiere información sobre los mismos (o sea que si se tuviera la información necesaria para evaluar el costo de la información que se desea comprar, dicha compra sería innecesaria); además, la diferencia en los costos marginales para el vendedor y el adquirente es enorme (y se aproxima a infinito en algunos casos) ya que la transferencia de la tecnología en nada disminuye su potencial. Véase K. Arrow, "Economic Welfare and the Allocation of Resources for Invention", en The Rate and Direction of Inventive Activity: Economic and Social Factors, Princeton University Press, 1962. Sobre las estrategias de negociación en la adquisición de tecnología, véase Constantino V. Vaitsos, "Income Generation and Income Distribution in the Foreign Direct Investment Model", Universidad Harvard, tesis doctoral, 1972. En particular el capítulo VII sobre la negociación en el modelo de tecnología y de inversión extranjera directa.

$80 \mathrm{La}$ creación del Registro Nacional de Transferencia de Tecnología es un gran adelanto sobre el régimen anterior, pero como se explica más adelante, debe ser complementado para aumentar su eficacia.

81 La vinculación con empresas extranjeras es un fenómeno muy extendido: el 85\% de las empresas entrevistadas en 1970 para un estudio afirmó estar vinculado con firmas extranjeras en cuanto a la adquisición de tecnología, equipo y materias primas. Véase Flavia Derossi, op. cit.

82 Véase el número 46 de la revista Investigación Fiscal (publicada por la Secretaría de Hacienda y Crédito Público), octubre de 1969. El estudio fue elaborado por la Dirección General del Impuesto sobre la Renta con datos en 1968, y solamente se refiere a pagos por asistencia técnica. 
Cuadro 7

MÉXICo: PAgos POR ASISTENCIA TÉCNICA POR PAÍS DE DESTINo, a 1968

\begin{tabular}{clcr}
\hline $\begin{array}{c}\text { Lugar que } \\
\text { ocupa }\end{array}$ & \multicolumn{1}{c}{ Pais } & $\begin{array}{c}\text { Monto } \\
\text { (pesos) }\end{array}$ & $\begin{array}{r}\text { \% del } \\
\text { total }\end{array}$ \\
\hline $1^{\circ}$ & Estados Unidos & 566771205 & 67.20 \\
$2^{\circ}$ & Panama & 59494628 & 7.10 \\
$3^{\circ}$ & Suiza & 55211221 & 6.50 \\
$7^{\circ}$ & Liechtens tein & 13579016 & 1.68 \\
$8^{\circ}$ & Inglaterra & 12053350 & 1.50 \\
$11^{\circ}$ & Bahamas & 9766177 & 1.20 \\
$13^{\circ}$ & Curazao & 4643696 & 0.55 \\
\hline
\end{tabular}

a El total de los pagos hechos a 32 países: $\$ 804709944$.

El estudio estuvo motivado por preocupaciones de índole fiscal (básicamente, el hecho de que pagos considerables se hicieran hacia países como Bahamas, Curazao, Panamá y Liechtenstein, todos ellos paraísos fiscales) así como por el hecho de que existieran pagos por conceptos no justificables de acuerdo con los giros de las empresas, ya que como el estudio observó, se encontraron "pagos por asistencia técnica a Panamá por parte de las compañías embotelladoras de refrescos". Los cuadros 7 y 8 muestran los países y los sectores industriales más importantes en términos de pagos por asistencia técnica. El hecho de que predominen los pagos hechos a los Estados Unidos revela una falta de mecanismo o procedimientos de búsqueda de tecnología a nivel mundial. En total, los pagos hechos por las empresas estudiadas sumaron 840709944 pesos (esta cantidad no incluye todos los pagos hechos por asistencia técnica en ese año, ni los pagos por concepto de regalías).

Como resultado de este estudio se reformó el régimen fiscal de los pagos al exterior por concepto de asistencia técnica. Antes de 1971, estos

\section{Cuadro 8}

MÉXICO: PAgos POR ASISTENCIA tÉCNICA POR RAMAS INDUSTRIALES Y COMERCIALES, a 1968

\begin{tabular}{|c|c|c|c|}
\hline $\begin{array}{l}\text { Lugar que } \\
\text { ooupa }\end{array}$ & $\begin{array}{c}\text { Ramas industriales } y \\
\text { oomeroiales }\end{array}$ & $\begin{array}{l}\text { Monto } \\
\text { (pesos) }\end{array}$ & $\begin{array}{l}\% \text { del } \\
\text { total }\end{array}$ \\
\hline $1^{\circ}$ & Laboratorios farmacGutioos & 99038858 & 11.30 \\
\hline $2^{\circ}$ & Industria automovillstioa & 77691462 & 9.20 \\
\hline $3^{\circ}$ & Aparatos el6otrioos & 55657622 & 6.90 \\
\hline $11^{\circ}$ & Productos alimentiolos & 27824954 & 3.45 \\
\hline $12^{\circ}$ & Herramientas y equipo industrial & 27482476 & 3.20 \\
\hline $14^{\circ}$ & Embotelladoras & 17399112 & 2.00 \\
\hline $19^{\circ}$ & Maquinaria en general & 13513890 & 1.67 \\
\hline $35^{\circ}$ & Agencias de publtoidad & 3704659 & 0.44 \\
\hline
\end{tabular}

a El total del estudio reveló datos sobre 76 ramas. El total para las empresas consideradas en estas 76 ramas: \$804 709944 . 
Cuadro 9

Pagos POR TRANSFERENCIA dE TECNOLOGía

\begin{tabular}{|c|c|c|c|}
\hline Pafo & Año & $\begin{array}{c}\text { Pagos por oonoep to do } \\
\text { tranisforenoig do } \\
\text { toonologia }\end{array}$ & $\begin{array}{l}\text { Pagos por toonologia } \\
\text { (poroiento de las } \\
\text { exportacionos totales) }\end{array}$ \\
\hline Argentina & 1969 & 127.7 & $7.9 \%$ \\
\hline Bras1l & $1966-1968^{\mathrm{b} /}$ & 59.6 & $3.4 \%$ \\
\hline Colombia & 1966 & 26.7 & $5.3 \%$ \\
\hline$x \in \times 100$ & 1968 & 200.0 & $15.9 \%$ \\
\hline Chile & 1969 & $8.2^{2 / 2}$ & $0.8 \%$ \\
\hline Vonezuele & 1969 & $6.1^{\circ}$ & $0.2 \%$ \\
\hline
\end{tabular}

Fuente: UNCTAD, “Transfer of Technology", TD/106, noviembre de 1971.

a Incluye pagos por patentes, licencias, conocimientos técnicos no patentados, marcas y servicios técnicos (millones de dólares).

b Promedio anual.

c No incluye servicios técnicos.

pagos habían estado gravados por una tasa fija proporcional del $20 \%$, en tanto que los pagos por concepto de regalías habían estado pagando un impuesto progresivo cuya tasa marginal máxima alcanzaba el $42 \%$. Con objeto de suprimir el incentivo a las empresas para canalizar como pagos por asistencia técnica los pagos de regalías, en enero de 1971 se igualaron los dos conceptos y desde entonces son objeto del impuesto progresivo de hasta $42 \%$. Esta medida provocó reacciones en el sector privado, en particular en la Confederación de Cámaras Industriales que declaró que "no estaba de acuerdo en declarar como un problema general el pago de regalías... ya que en realidad (la asistencia técnica) viene a compensar nuestras deficiencias en materia de IDE".83 Por otra parte, fue criticada por gravar un mecanismo que puede ser muy útil para la transferencia de tecnología (como lo es la asistencia técnica) con un impuesto idéntico al de un canal que en ocasiones puede serlo menos para la transmisión de conocimientos técnicos (caso de licencias para el uso y explotación de patentes y que requieren del pago de una regalía calculada normalmente sobre las ventas netas).$^{84}$

En todo caso, estas medidas no fueron suficientes para reducir los costos explícitos o implícitos derivados de la importación de tecnología. Un estudio para la UNCTAD sobre la experiencia de varios países reveló que en 1968 México gastaba aproximadamente unos 200 millones de dólares por concepto de patentes, licencias, conocimientos técnicos patenta-

83 Véase "La cuestión de las remesas por asistencia técnica" en la "Sección Nacional", Comercio Exterior, diciembre de 1969.

84 Véase la nota de Carlos Vidale Carbajal, "Comentario sobre las reformas fiscales para 1971", Comercio Exterior, marzo de 1971, p. 222. Para este autor, la solución ideal hubiera consistido en el perfeccionamiento de las medidas de vigilancia para verificar la concesión de un trato preferencial a la asistencia técnica. Sin embargo, no se puede decir que exista un consenso en la literatura sobre la superioridad de un canal de transferencia de tecnología sobre otro. 
dos, marcas y servicios técnicos. Además de que estos pagos incluyen conceptos que no pueden considerarse como tecnología (marcas y nombres comerciales), se estimó que para el período 1953-1968, los pagos se incrementaron a un ritmo de cerca de $19 \%$ anual. ${ }^{85}$ Como se desprende del cuadro 9, en comparación con otros países de la región, los pagos hechos por México resultan exorbitantes.

Además, cabe señalar que en esta estimación no están incluidos los pagos indirectos que son el corolario de las cláusulas incluidas frecuentemente en los contratos de transferencia de tecnología, y que obligan al comprador de la tecnología a adquirir exclusivamente del proveedor una serie de insumos (materias primas, productos intermedios, equipo, bienes de capital, servicios de ingeniería). Al vincular estos bienes a los conocimientos técnicos objeto del contrato se les otorgan las mismas características monopólicas inherentes a la tecnología y en consecuencia los sobreprecios que se pueden cargar aumentan las ventajas monopólicas del vendedor de la tecnología. En México existen indicios de que se cargan sobreprecios al igual que en otros países. Un estudio reciente ${ }^{86}$ encontró que de 13 productos importados por empresas farmacéuticas que operaban en México 12 eran pagados a precios superiores a las cotizaciones en el mercado internacional. El cuadro 10 da una idea de la importancia del fenómeno.

Por otra parte, las cláusulas que obligan al receptor a realizar compras atadas no son las únicas cláusulas restrictivas. Otro estudio de UNCTAD realizado sobre una muestra de 109 contratos de transferencia de tecnología arrojó los siguientes resultados: se encontraron 126 cláusulas con restricciones a la exportación (de las cuales 53 eran prohibiciones totales, en 12 casos se estipulaba la previa aprobación del dueño de la tecnología para poder exportar y 19 cláusulas contenían restricciones sobre los patrones de producción) ${ }^{87}$

Existe además un costo social implícito en la transferencia de tecnología tal y como se lleva a cabo en México. Este costo social se deriva del patrón de consumo al que están asociadas las importaciones de tecnología. Así, la excesiva e indiscriminada vinculación tecnológica con firmas extranjeras sugiere que el crecimiento de los ingresos no acompañado por la redistribución del ingreso total dirige la composición de la demanda global hacia productos con una alta elasticidad ingreso cuyo contenido de importaciones es mayor que el de los productos cuya demanda evoluciona lentamente. Estas tendencias registradas en la composición de la demanda contrarrestan los logros de la estrategia de sustitución de importaciones. En un país con una alta concentración del ingreso, la estructura de la demanda final tiende a favorecer una ineficiente asignación de recursos hacia la producción de bienes de consumo suntuario. Ade-

85 UNCTAD, “Transfer of Technology”, TD/106, noviembre de 1971. Este documento fue presentado a la Tercera Reunión de la UNCTAD celebrada en Santiago de Chile, abril de 1972.

86 Bueno, Navarrete y Wionczek, op. cit.

87 Véase UNCTAD, "Prácticas comerciales restrictivas”, TO/B/C/2/104, Ginebra. 
Cuadro 10

MÉXICO: SOBREPRECIOS EN LA INDUSTRIA FARMACÉUtiCA, 1968

\begin{tabular}{|c|c|c|c|c|}
\hline Producto & $\begin{array}{l}\text { Preoio } \\
\text { internacional } \\
\text { ares por kilogramo) }\end{array}$ & $\begin{array}{l}\text { Preolo de } \\
\text { importaciones en Kóxico } \\
\text { (dólares por kilogramo) }\end{array}$ & $\begin{array}{l}\text { Sobre } \\
\text { preoio } \\
(\%)\end{array}$ & $\begin{array}{c}\text { Cantidad } \\
\text { Importada } \\
\text { (miles de pesos }\end{array}$ \\
\hline $\begin{array}{l}\text { Clorhidrato de } \\
\text { tetraoiolina }\end{array}$ & 23.38 & 32.93 & 40.8 & 1793 \\
\hline Tetraciolina & 24.71 & 61.02 & 146.9 & 1029 \\
\hline Oxitetraoiolina & 30.04 & 43.20 & 43.8 & N.D. \\
\hline Triamoinolona & 7033.33 & 7571.63 & 7.7 & 8991 \\
\hline $\begin{array}{l}\text { Clorhidrato de } \\
\text { olortetraojolina }\end{array}$ & 30.00 & 455.44 & 1418.1 & 1941 \\
\hline $\begin{array}{l}\text { Suooinato de } \\
\text { oloramfeniool }\end{array}$ & 31.90 & 67.92 & 112.9 & 1605 \\
\hline Cloramfeniool & 13.50 & 26.96 & 99.7 & 11390 \\
\hline $\begin{array}{l}\text { 21-Posfato-disbdioo } \\
\text { de prednisolona }\end{array}$ & 620.00 & 4200.00 & 577.4 & 431 \\
\hline Patentonato de caloio & 3.30 & 10.80 & 227.3 & $28^{\mathrm{a} /}$ \\
\hline Clorodiasepóxida & 19.68 & 224.97 & 1043.1 & H.D. \\
\hline Diazepam & 37.76 & 668.05 & 1669.2 & N.D. \\
\hline Testosterona & 260.00 & 94.52 & -063.2 & $2^{a / i}$ \\
\hline Progeaterona & 120.00 & 595.44 & 396.2 & $859^{\mathrm{g} /}$ \\
\hline
\end{tabular}

Fuente: G. Bueno, Navarrete y Wionczek, "La transferencia internacional de tecnología a nivel de empresa: el caso de México", preparado para la División de Hacienda Pública de las Naciones Unidas, México, 1971 (mimeografiado). El cuadro fue elaborado con base en los datos de Constantino V. Vaitsos para los precios internacionales (promedio de las cotizaciones máximas-mínimas). Estos datos aparecen en su trabajo "Transfer of Resources and Preservation of Monopoly Rents" (documento presentado en la Conferencia de Dubrovnik de Harvard University, DAS). Para los precios de importación de México, los autores utilizaron datos de la Dirección General de Estadística. Se le agregó la columna sobre la cantidad importada, con base en datos de la propia Dirección General de Estadística.

a Datos para 1970.

N.D. $=$ No disponible.

más, si bien no existen cifras sobre el monto de los pagos por el uso de marcas y nombres comerciales provenientes del exterior, no hay indicios de que dichos pagos sean reducidos.

En 1972 se creó el Registro Nacional de Transferencia de Tecnología con el objeto de regular el proceso de transferencia de tecnología en sus diferentes aspectos. Ante la ausencia de una política explícita de desarrollo industrial que determine prioridades para una industrialización selectiva, el potencial de este instrumento como mecanismo de orientación para la adquisición de tecnología en el extranjero se ve seriamente mermado. ${ }^{88}$ Además, sin que se lleve a cabo una reforma del actual régimen de propiedad industrial no podrá impedirse la realización de pagos no justificados ni la existencia de una serie de prácticas restrictivas.

88 Tampoco se complementó el Registro con un incentivo para destinar fondos a la IDE. 
Sin embargo, el Registro representa un enorme adelanto sobre el régimen anterior que básicamente estaba animado por preocupaciones de pagos excesivos y evasión fiscal. ${ }^{89}$ De acuerdo con la ley que lo crea, es obligatoria la inscripción en el Registro de los documentos en donde estén contenidos los actos relativos a los siguientes elementos:

i) concesión del uso o la autorización de explotación de marcas, patentes de invención, mejoras, modelos y dibujos industriales;

ii) suministro de conocimientos técnicos y provisión de ingeniería básica y de detalle;

iii) asistencia técnica y servicios de administración y operación de empresas.

Si no se lleva a cabo la inscripción del contrato, éste no surte efectos legales entre las partes. Además, la ley señala los casos en los que el contrato no será registrado. Los casos más importantes son:

a) cuando al precio o la contraprestación no guarden relación con la tecnología adquirida o constituyan un gravamen injustificado y excesivo para la economía nacional;

b) cuando se incluyen cláusulas por las cuales se permita al proveedor regular o intervenir, directa o indirectamente, en la administración del adquirente de tecnología;

c) cuando se establezca la obligación de adquirir equipos, herramientas, partes o materias primas exclusivamente de un origen determinado;

d) cuando se prohíba o limite la exportación de los bienes o servicios producidos por el adquirente de manera contraria a los intereses del país;

e) cuando se establezca la obligación de vender de manera exclusiva al proveedor de la tecnología los bienes producidos por el adquirente;

f) cuando se establezcan plazos excesivos de vigencia. En ningún caso dichos plazos podrán exceder de diez años obligatorios para el adquirente.

El proyecto de Ley fue objeto de serias polémicas. Indudablemente las presiones ejercidas por algunos sectores fueron la causa de que no se complementara este instrumento. Entre las cláusulas que no fueron incluidas sobresalen las de prohibición de la capitalización de la tecnología

89 Además del régimen fiscal sobre los pagos por concepto de asistencia técnica y regalías (véase la página 301), la Secretaría de Industria y Comercio exige la presentación de los contratos tecnológicos a las empresas que solicitan beneficios fiscales derivados de la Ley de Industrias Nuevas y Necesarias, así como a las empresas que desean acogerse a los beneficios otorgados por los programas de fabricación que maneja dicha Secretaría. El propósito era mantener los pagos de regalías dentro del límite máximo del $3 \%$ de las ventas netas de las empresas solicitantes. En 1972 se hizo extensivo este criterio para las empresas que deseen disfrutar los beneficios del Decreto de Descentralización de la Industria. Véase el artículo 22, fracción II del Decreto del 19 de julio de 1972 (publicado el día siguiente en el Diario Oficial). 
(equity participation); no se fomenta la inclusión de la cláusula de sublicenciamiento (que permitiría la compra centralizada de tecnología); tampocu se incluyó la prohibición expresa de las cláusulas que obligan al receptor de la tecnología a realizar gastos de publicidad comercial.

Hasta abril de 1974 se habían presentado 5625 contratos al Registro Nacional de Transferencia de Tecnología. El $73 \%$ se presentó a "toma de nota" para conocimiento del Registro pero sin que se juzgara el fondo de dichos contratos ya que por haberse celebrado con anterioridad a la promulgación de la ley cuentan con un plazo de dos años para ajustarse a las disposiciones de la misma. ${ }^{90} \mathrm{El}$ resto (1 513 contratos) se presentó para su inscripción en el Registro y hasta abril de 1974 ya se habían emitido 834 resoluciones: 535 positivas y 299 negativas por contener los contratos una o más violaciones a la ley. Las violaciones que aparecieron con mayor frecuencia en las resoluciones negativas fueron:

a) contraprestación excesiva o que no guardaba relación con la tecnología objeto del contrato $(81 \%$ de las resoluciones negativas mencionaban esta violación) ;

b) establecimiento de plazos excesivos de vigencia (40\% de las resoluciones negativas);

c) restricciones a las exportaciones ( $26 \%$ de esas resoluciones);

d) restricciones al desarrollo tecnológico del adquirente $(26 \%)$;

e) limitación a volúmenes de producción y la imposición de precios de venta $(39 \%)$;

f) obligación de ceder al otorgante las patentes o innovaciones que obtenga el adquirente $(24 \%)$.

Estas resoluciones fueron dictadas en primera instancia y aproximadamente una tercera parte de los contratos rechazados fueron renegociados, modificados y aprobados por el Registro. Este instrumento de política busca así racionalizar la importación de conocimientos técnicos y ha tenido un impacto importante en el ahorro de divisas, apertura de mercados de exportación que antes estaban prácticamente vedados para los productos de manufactura nacional y en general en el aumento del poder de negociación de las empresas pequeñas y medianas mexicanas.

El Registro opera en contacto estrecho con el Consejo Nacional de Ciencia y Tecnología y otras instituciones para fundamentar sus resoluciones desde el punto de vista técnico, económico y jurídico. Aunque el establecimiento del Registro de Transferencia de Tecnología es un paso importante para la formulación de una política en materia de importación de tecnología, es necesario reconocer que queda mucho por hacerse y que este mecanismo debe ser complementado con otros que permitan una absorción y adaptación de la tecnología extranjera a los requerimientos del desarrollo socioeconómico nacional.

90 Mauricio de María y Campos, "La política mexicana sobre la transferencia de tecnología: una apreciación preliminar", Comercio Exterior, Vol. XXIV, mayo de 1974. 